\title{
Hyperthermia and Temperature-Sensitive Nanomaterials for Spatiotemporal Drug Delivery to Solid Tumors
}

\author{
Mohamadreza Amin ${ }^{1,2}$, Wenqiu Huang ${ }^{1}$, Ann L. B. Seynhaeve ${ }^{1}$ and Timo L. M. ten Hagen ${ }^{1,2, *}$ \\ 1 Laboratory of Experimental Oncology (LEO), Department of Pathology, Erasmus Medical Center, \\ 3015GE Rotterdam, The Netherlands; m.amin@erasmusmc.nl (M.A.); w.huang@erasmusmc.nl (W.H.); \\ a.seynhaeve@erasmusmc.nl (A.L.B.S.) \\ 2 Nanomedicine Innovation Center Erasmus (NICE), Erasmus Medical Center, \\ 3015GE Rotterdam, The Netherlands \\ * Correspondence: t.l.m.tenhagen@erasmusmc.nl; Tel.: +31-10-704-3682
}

Received: 23 September 2020; Accepted: 19 October 2020; Published: 22 October 2020

\begin{abstract}
Nanotechnology has great capability in formulation, reduction of side effects, and enhancing pharmacokinetics of chemotherapeutics by designing stable or long circulating nano-carriers. However, effective drug delivery at the cellular level by means of such carriers is still unsatisfactory. One promising approach is using spatiotemporal drug release by means of nanoparticles with the capacity for content release triggered by internal or external stimuli. Among different stimuli, interests for application of external heat, hyperthermia, is growing. Advanced technology, ease of application and most importantly high level of control over applied heat, and as a result triggered release, and the adjuvant effect of hyperthermia in enhancing therapeutic response of chemotherapeutics, i.e., thermochemotherapy, make hyperthermia a great stimulus for triggered drug release. Therefore, a variety of temperature sensitive nano-carriers, lipid or/and polymeric based, have been fabricated and studied. Importantly, in order to achieve an efficient therapeutic outcome, and taking the advantages of thermochemotherapy into consideration, release characteristics from nano-carriers should fit with applicable clinical thermal setting. Here we introduce and discuss the application of the three most studied temperature sensitive nanoparticles with emphasis on release behavior and its importance regarding applicability and therapeutic potentials.
\end{abstract}

Keywords: hyperthermia; temperature sensitive nanoparticles; liposomes; polymeric nanoparticles; triggered drug release

\section{Introduction}

For a chemotherapeutic drug to be effective the concentration reaching the target site (e.g., the tumor) needs to be sufficient enough to eradicate all tumor cells, which is one of the major challenges in chemotherapy. Often the high cytotoxic activity of a therapeutic compound observed in vitro is not matched after administration in animal models or patients. When injected into the bloodstream low-molecular weight chemotherapeutic agents exhibit short plasma half-lives due to distribution throughout the entire body, fast clearance, neutralization, or degradation. While the large volume of distribution and fast clearance rate negatively impact intratumoral drug concentrations and exposure time in the tumor tissue [1], toxic effect on normal tissues or excreting organs simply make dose increase not an option [2].

Encapsulating chemotherapeutic agents into a carrier not only enables administration of poor water soluble drugs [3-5] or preserves drugs from inactivation and degradation [6-8], it significantly reduces the exposure of normal tissues to chemotherapeutics by decreasing the distribution volume, 
which is under ideal circumstance a restriction to the blood pool, therefore lessening unwanted side effects on normal tissues. Modifications such as making nano-sized particles and PEGylation, which is the addition of polyethylene glycol to diminish recognition by macrophages, detract recognition of nanoparticle by the reticuloendothelial system (RES, i.e., macrophages) [9], and together with stable association of the encapsulated drug with the vehicle, grant a prolonged circulation of drugs in blood. In principle such modifications aim at taking advantage of pathological features of tumors where permeation into the tumor is enhanced due to fenestrated tumor vasculature and nanoparticles are retained inside tumors due to a lack of a functional lymphatic drainage; a mechanism known as enhanced permeation and retention (EPR) effect [10,11], and so far EPR-based passive targeting was the central paradigm in cancer nanomedicine. It has been shown that encapsulation of doxorubicin (DXR) in nano-sized PEGylated liposomes resulted in 250-fold reduced clearance rate and 60-fold reduced volume of distribution to $5.9 \mathrm{~L}$ compared to $365 \mathrm{~L}$ for free DXR when administered in a dose of $50 \mathrm{mg} / \mathrm{m}^{2}$ in humans [12], minifying the main dose-limiting cardiotoxicity associated with DXR treatment [13]. Meanwhile, compared to free DXR, higher accumulation of liposomal DXR in tumor has been achieved [14-17]. In this respect several clinically approved nanoparticles have been developed for treatment of cancer. However, the clinical success of these nanodrugs mostly relies on reduced side effect rather than improved antitumor efficacy.

In addition to features of a tumor that are in favor of drug delivery based on EPR, there are several barriers limiting a predictable and effective drug accumulation inside the tumor. Heterogeneous blood supply resulting in hyper-perfused and non-perfused areas prevents a homogenous drug distribution. Additionally, high interstitial fluid pressure and high levels of matrix proteins limit systemic administered drug escaping the blood flow and entering the tumor interstitium. Tumors tend to have an abundance of fibroblasts and infiltrating immune cells re-designed towards a pro-tumoral status. These cells also absorb drugs lowering the availability for malignant cells. Cytotoxic drug levels do not reach all cancer cells causing re-growth of the partially affected tumor. Moreover, heterogeneous drug delivery creates concentration gradients leading to regions with non-cytotoxic drug levels, which may cause drug resistance [18-25]. Therefore, manipulating the tumor microenvironment to increase perfusion, permeability, and extravasation, or even normalization of tumor vasculatures, were found to enhance drug delivery in tumors [26-29]. A dense extracellular matrix in a tumor not only correlates with a high interstitial fluid pressure but also prevents distribution of drugs into deeper regions by decreasing the diffusive or convective movements of drugs inside the tumor interstitial space [30]. This holds true for both free and encapsulated chemotherapeutics but becomes more significant for nanoparticles compared to free drug molecules as a result of a larger size. An effective EPR relies on a homogenous distribution and permeability of the tumor-associated vasculature, which is more than often not the case. Vessel growth in a tumor is very heterogeneous resulting in hyper-vascularized versus non-vascularized areas, mature versus immature (leaky) vessels, and a functional blood flow versus stasis. This results in a very heterogeneous blood supply, nanoparticle delivery, and extravasation [31,32]. Even extravasated nanoparticles remain predominantly in the perivascular region and only minimal amounts penetrate into the tumor interstitium further $[25,33,34]$. Tumor heterogeneity imposes significant limitations on effective delivery of nanoparticles to tumors and is not only observed spatially within a tumor [35,36], but between individual tumors [37] and is dependent on the size, location, and most importantly growth rate. Compared to model murine tumors, human tumors grow slower making this heterogeneity even more prominent. It seems that passive accumulation of nanoparticles in a tumor via the EPR effect is not that effective in human cancer and worth mentioning that the concept of enhanced permeation i.e., extravasation of nanoparticles through inter-endothelial gaps present in tumor blood vessels, is now under serious debate $[38,39]$.

Next to challenges with delivery to tumor, cellular availability of drugs encapsulated in nanoparticles is another challenge. For an encapsulated drug to become biologically active it is important that the drug dissociates from the carrier. As stated earlier most of the nanoparticles are built to be stable during circulation in blood or are devised to be unrecognizable by reticuloendothelial 
system (RES) (coined as stealth), in order to ensure a long blood circulation, which is a prerequisite for tumor accumulation. However, upon entering the tumor interstitium that stability or stealthiness turns against effective delivery of drugs to cells where only free drug molecules can be functional. It could be said that in general content release has been sacrificed in the favor of nanoparticle stability, although release of the drug is essential to achieve a therapeutic response. When PEGylated liposomal doxorubicin (PLD) extravasates into the tumor interstitium minimal DXR release or interactions with cells is observed due to the rigid liposome membrane and presence of Polyethylene glycol molecules. As a result, it remains inside the tumor for a long period of time and DXR delivery to cells mainly takes place upon degradation of liposomes in a slow process over several days [31,40]. We showed that even the liposomes taken up by cells remain intact inside the endosomal/lysosomal system for several days [31,32,41]. Therefore, accumulation of nanoparticles in a tumor does not imply cellular availability of the content or that targeting of subcellular structures occurs [42].

One approach to enhance cellular delivery is by using ligand-mediated internalization, where nanoparticles decorated with ligands that interact with appropriate receptors on cells are being taken up by endocytosis. However, despite numerous studies none of the preclinically accepted ligand-modified nanocarriers have shown enough clinical benefit to reach the market. Despite ligand-modification of nanoparticles enhances internalization into cells, it has been shown that cellular level of drugs delivered into cells does not necessarily imply the availability of free drug molecules to affect the subcellular targets [41]. Moreover, all problems related to inefficient drug delivery to tumor through nanoparticles still exist since active targeting of tumor cells relies first on passive extravasation to reach the targeted cells. In addition, ligand modification negatively impacts on pharmacokinetics and distribution of nanoparticles; while ligand modification reduces circulation lifetime of nanoparticles, because of augmented clearance rate, which in turn decreases tumor accumulation [43-45], addition of an avidity to nanoparticles results in a prompt interaction with tumor cells soon after extravasation, limiting distribution and penetration of nanoparticles deeper into the tumor [41].

The crucial importance of delivering free drug to tumor cells prompted researchers to exploit pathological features of tumor microenvironment, including reduced $\mathrm{pH}[46,47]$, increased enzymatic [48] or redox [49] activities, and design nanoparticles releasing payload in response to these endogenous stimuli [50-54]. However, regions with the appropriate climate are heterogeneously distributed throughout the tumor, response to these stimuli is often slow and uncontrollable, and the small difference between normal and malignant tissue necessitates vehicles responsive to a narrow range of differences. Furthermore, delivery of such endogenous trigger-sensitive nanoparticles again relies on passive accumulation. In contrast to endogenous stimuli, exogenous stimuli such as heat, ultrasound [55-57], light [58,59], and radio frequency electromagnetic fields [60,61] provide a great spatiotemporal control over triggering the release from nanoparticles. Among these ultrasound $[62,63]$ and mild hyperthermia $[40,64,65]$ have an additional advantage to enhance tumor permeability and have been employed to improve tumor accumulation of nanomedicines.

Here we focus on the use of mild hyperthermia (e.g., $42^{\circ} \mathrm{C}$ ) in the steered delivery and release of coadministered nanoparticles. Thermosensitive nanoparticles can be constructed that are stable in the blood flow (i.e., at temperatures of $37^{\circ} \mathrm{C}$ ) and release their content when a higher temperature is applied at the tumor site.

\section{Hyperthermia and Its Clinical Application}

Hyperthermia in treatment of cancer is defined as raising the temperature of tumor locally or systemically by external means and it is now being regarded as the fifth modality of treatment, next to surgery, chemotherapy, radiotherapy, and immune-therapy.

The application of local or systemic hyperthermia for cancer therapy goes back to around 3000 B.C when, for example, the so-called "fire drills" (hot blades and sticks) were being used for the treatment of breast cancer [66]. 
Application of local hyperthermia can roughly be divided into two strategies. Thermal ablation with temperature above $50^{\circ} \mathrm{C}$ and mild hyperthermia using temperatures around $41-45^{\circ} \mathrm{C}$. The high temperature used in ablation irreversibly damages cellular structures, directly killing cells and destroying tissue and matrix components as well as the vasculature, leading to immediate tissue destruction. This is mostly suitable for organ confined tumors, such as hepatocellular carcinomas, however, as the tumor spreads in the surrounding tissue not all cells will be effectively ablated.

Mild hyperthermia can directly and indirectly affect tumor cells. Cells located in regions of the tumor with poor blood flow have higher sensitivity to heat due to the hypoxic and acidic condition and could be selectively killed by application of this type of heat [67-69]. Due to mild hyperthermia cell membrane permeability and tumor perfusion are increased and capability of repairing DNA damages is disturbed [70]. These, on the one hand result in greater drug delivery to tumor and cells, and on the other hand increase the sensitivity of cells to chemotherapeutics and radiation, boosting the effect of chemotherapy and radiotherapy when combined with hyperthermia [71,72]. In addition, mild hyperthermia can induce or improve antitumor activity [73-76]. For example, many of the heat-shock proteins (HSPs) released from heat-stressed cancer cells can activate antigen-presenting cells (APCs) [77-79].

A standard chemotherapy protocol, including doxorubicin, in combination with regional mild hyperthermia has been shown to improve significantly the short-time and long-time survival of soft tissue sarcoma patients as compared to chemotherapy alone [80,81], most likely because of altered cellular processes, including DNA repair, change in the tumor microenvironment, and anticancer immunity induced by hyperthermia [82].

In addition to these effects mild hyperthermia also increases the permeability of tumor vasculature by enlarging pore size in the endothelial lining, facilitating nanoparticle extravasation, which, alongside increased perfusion, improves accumulation of liposomes [83-85] or free drug [86,87] inside the tumor interstitium (Figure 1). Enlargement of gaps in the endothelial lining is specific for the tumor-associated vasculature and is reversible after approximately $8 \mathrm{~h}$ [64].

(a)

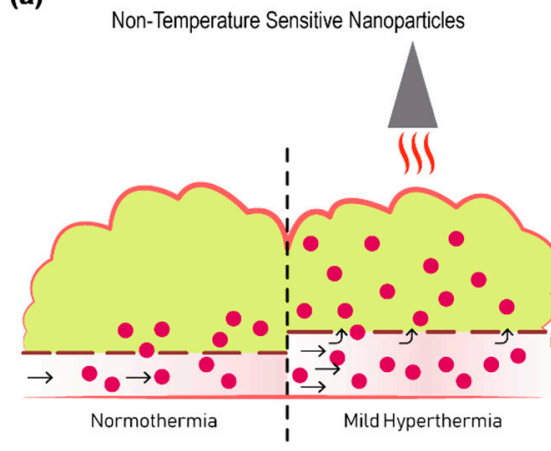

(b)

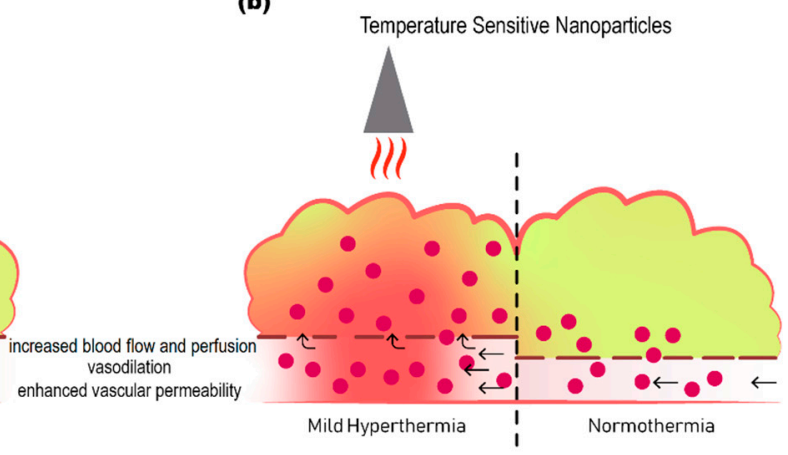

Figure 1. Schematic representation of the effect of mild hyperthermia on drug delivery to tumors. Delivery of non-temperature sensitive nanoparticles (a), or temperature sensitive nanoparticles (b) to tumor is enhanced by application of mild hyperthermia. Mild hyperthermia increases regional blood flow and perfusion, causes vasodilation, and increases vascular permeability, resulting in increased extravasation and more homogeneous distribution of nanoparticles deeper into the tumor. When combined with temperature sensitive nanoparticles the additional advantage is increased cellular delivery of free drug upon release from the nanoparticles in response to heat.

Delivery of chemotherapeutic agents in a spatiotemporal controlled manner has long been a dilemma in the field of drug delivery. We believe that with good knowledge of the biology, and the unique features of the tumor tissue subjected to heat, and the advanced methods and instruments that enabled precisely controlled application of hyperthermia at desired regions, heat triggered drug release from temperature sensitive nano-devices is the most advanced and promising strategy to fulfill 
the concept of the magic bullet. However, the rate and magnitude of release from such nanoparticles are crucial with respect to efficient drug delivery. Herein we discuss the advances made with designing three main classes of temperature sensitive nanoparticles.

\section{Thermosensitive Liposomes (TSLs)}

Liposomes are spherical vesicles of one or multi layers of lipid bilayer phase, mainly composed of phospholipids, and spontaneously formed by self-assembly of amphipathic lipids upon exposure to aqueous environment. Unique features such as ease of preparation and modification, biocompatibility, biodegradability, capability of carrying variety of compounds either inside the aqueous core or inside the hydrophobic part of the membrane or on the surface of liposomes make them powerful tools for drug delivery. In addition, the advent of remote loading methods by which weak acidic or weak basic drug molecules could be encapsulated in liposomes at high concentration with high encapsulation efficiency, together with the high captured volume inside liposomes which provides ample space for encapsulation of hydrophilic molecules, allows efficient delivery.

A unique feature of phospholipid bilayers is the ability to undergo a reversible thermotropic gel-to-liquid crystalline phase transition (Tc). In the gel state, the hydrocarbon chains of phospholipids are fully extended, packed closely side-by-side, and aligned almost perpendicular to the liposomes surface plain. As a result, phospholipids occupy the minimal cross-sectional area, and thickness of the bilayer is at a maximum $(5.0-5.5 \mathrm{~nm})$, depending of the length of acyl chain. Such highly ordered packing restricts intra- and intermolecular motions establishing a highly impermeable membrane. In the liquid crystalline state the acyl chains are more mobile towards the terminus of the acyl chain in the center of the bilayer, and flap around and tilt more at the glycerol backbone, resulting in increased effective cross-sectional area of phospholipid molecules and reduction of the bilayer thickness to about $4.0-4.5 \mathrm{~nm}$. Consequently, membranes at the liquid crystalline phase are typically more permeable $[88,89]$. However, the highest permeability or release from liposomes is observed during this transition. Papahadjopoulos et al. found that self-diffusion rates of $22 \mathrm{Na}^{+}$or $14 \mathrm{C}$-sucrose through liposomes composed of DPPG or DPPC increase by increasing temperature and reach a maximum at temperatures close to transition temperature of the lipids, but after that release decreases with further increasing temperature $[90,91]$. The most compelling explanation for that, which is still accepted as the mechanism of release from temperature sensitive liposomes (TSLs), was suggested to be attributed to a transient formation of microscopic regions of disorder, later called "grain boundaries", between domains of phospholipids in gel phase and domains of phospholipids in liquid phase that coexist within a membrane plane [90] (Figure 2a). Followed by increasing the temperature fraction of such disordered boundaries reduces as the membrane is predominantly in a liquid-like phase. In addition, when transition behavior of liposomes was abolished by addition of $50 \mathrm{~mol} \%$ cholesterol the release was also completely attenuated. Evidence of coexisting clusters of gel and liquid crystalline phases have been observed in liposomes composed of DOPC and DSPC [92]. Considering these boundaries as the releasing sites in liposome membranes was also fit and predicted by mathematical modeling [90].

This property of release at the transition temperature was for the first time exploited by Yatvin and coworkers [93] to design liposomes with transition temperatures above $37^{\circ} \mathrm{C}$ but attainable by mild hyperthermia, using DPPC-based liposomes. Liposomes composed of pure DPPC start to release encapsulated $\mathrm{CF}$ at around $30{ }^{\circ} \mathrm{C}$ and reach a maximum release at ca. $38^{\circ} \mathrm{C}$. Addition of $25 \mathrm{~mol} \%$ DSPC to DPPC results in a sharper release at elevated temperatures. Onset temperature of release increases to ca. $41{ }^{\circ} \mathrm{C}$, and maximum release was achieved at $45^{\circ} \mathrm{C}$, and prephase transition behavior observed in pure DPPC was abolished. It was also found that presence of serum is in favor of release by enhancing the magnitude of release without changing release temperature. Since then DPPC:DSPC mixtures were employed for making thermosensitive liposomes (TSLs). Later it was observed that injection of TSLs composed of DPPC:DSPC (70:30 mol\%) encapsulating Methotrexate (MTX) into mice bearing a Lewis lung carcinoma resulted in almost three times higher levels of MTX $4 \mathrm{~h}$ after injection when the tumor was heated at $42^{\circ} \mathrm{C}$ for $15 \mathrm{~min}$ before and $1 \mathrm{~h}$ after injection compared to unheated 
tumors $[91,94,95]$. The therapeutic benefit of TSLs containing cis-Dichlorodiammineplatinum(11) was then evaluated in mice bearing sarcoma 180 tumors. Injection of liposomes plus mild hyperthermia applied as above resulted in greater drug uptake and longer tumor growth delay following treatment, which was equal to treatment with 2.5-fold higher dose of free drug plus mild hyperthermia [95]. However, the release rates from these liposomes is relatively slow [93-95]. Iga et al. [96] found that decreasing DSPC to $10 \mathrm{~mol} \%$ resulted in faster and higher release compared to formulations with higher DSPC content. It was also found that the release is also affected by liposome size as larger liposomes are more sensitive to heat compared to smaller liposomes.

(a)

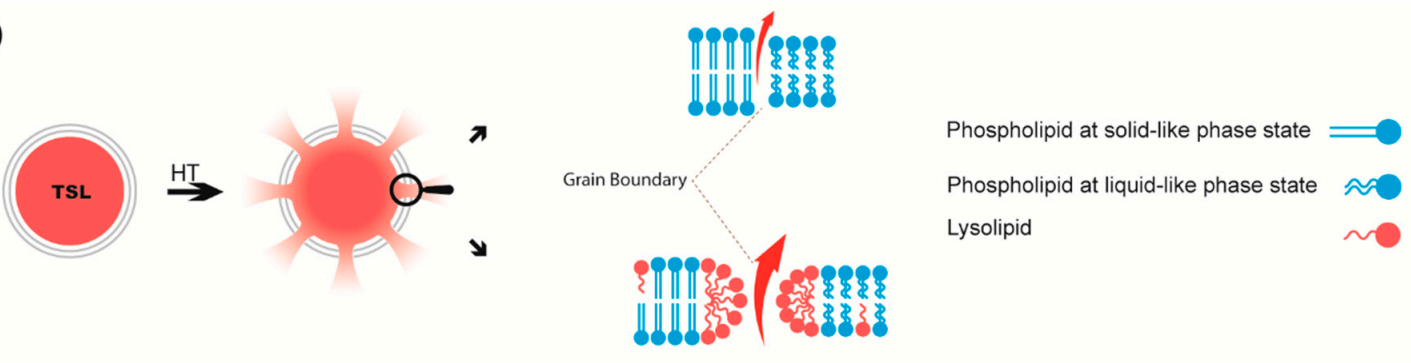

(b)

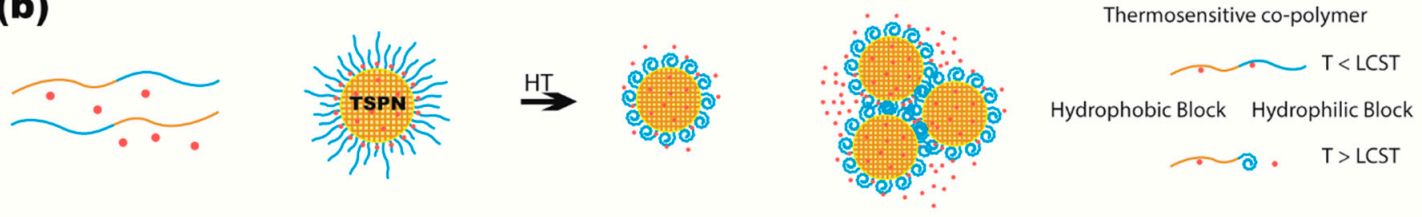

(c) $)$ (
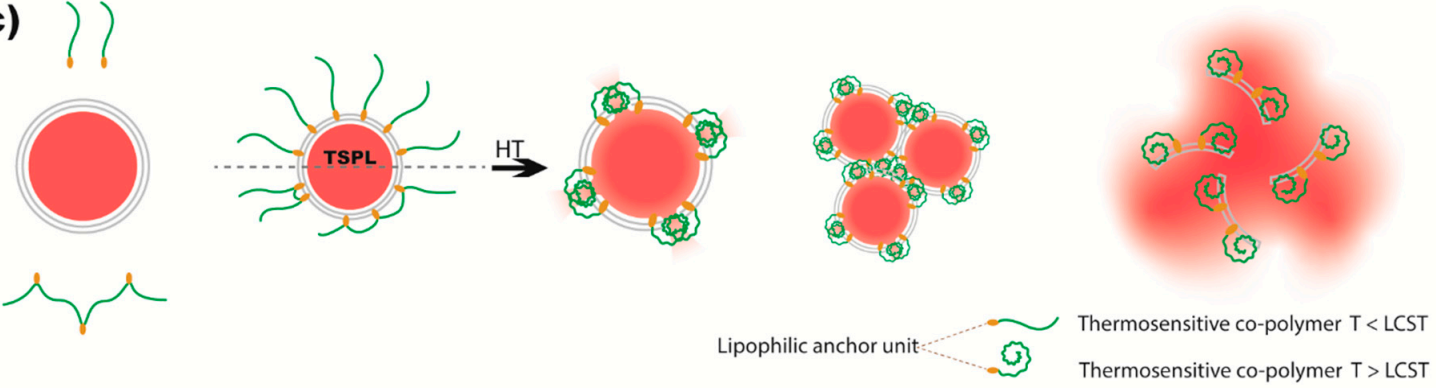

Figure 2. Schematic representation of postulated mechanisms of drug release from different temperature sensitive nanoparticles in response to exposure to hyperthermia (HT). (a) Upon heating of a temperature sensitive liposome (TSL) phospholipids grain boundaries form between coexisting phospholipids of solid-like and liquid-like states from which encapsulated drug releases. Presence of lysolipids stabilizes the grain boundaries leading to ultrafast drug release from the liposome at hyperthermia condition. (b) At temperatures $(\mathrm{T})$ below the release temperature (lower critical solution temperature, LCST) of temperature sensitive copolymers, from which temperature sensitive polymeric nanoparticles (TSPN) have been formed, the outer shell of the nanoparticle consists of fully hydrated and stretched polymers. By increasing the temperature higher, the hydrated outer shell collapses by losing hydrophilicity and becomes hydrophobic which leads to drug release and aggregation of TSPN. (c) Upon heating of liposomes modified with temperature sensitive polymers (TSPL) to temperatures above the LCST, the temperature sensitive motifs of copolymers lose hydrophilic reactions and tend to interact with hydrophobic regions of phospholipid bilayers which results in drug release, aggregation, or disintegration of liposomes.

In addition to release properties the studied TSLs revealed fast clearance rates [94,95]. Maruyama et al. [97] increased the circulation time of TSLs by addition of $6 \mathrm{~mol} \%$ ganglioside GM1 (GM1) to DPPC:DSPC (90:10) lipid mixture which resulted in 2.5 times increased tumor accumulation compared to TSLs without GM1. However, their TSLs released 45\% of the loaded DXR after 5 min 
incubation at $42{ }^{\circ} \mathrm{C}$ in $20 \%$ serum. As stated earlier, addition of $50 \mathrm{~mol} \%$ cholesterol into liposomes abolishes phase transition behavior and improves leakage stability of liposomes. In fact, the leakage stability of Doxil, a clinically approved form of liposomal doxorubicin, is partly attributed to the presence of $40 \%$ cholesterol in the lipid membrane. However, at lower contents of cholesterol endothermic events occur, but at lower extent negatively correlating with cholesterol content. Based on this Papahadjopoulos and colleagues employed cholesterol at low content and PEGylation to increase stability of TSLs while preserving the thermal responsiveness [98]. Their optimized TSLs composed of DPPC:HSPC:Chol:mPEG2000-DSPE (54:27:16:3 mol\%) showed minimal leakage during $30 \mathrm{~min}$ incubation at $37^{\circ} \mathrm{C}$ in presence of $50 \%$ bovine serum, whereas TSLs composed of DPPC:HSPC $(67: 33 \mathrm{~mol} \%)$ released $50 \%$ of DXR content at this condition. However, addition of cholesterol negatively reduces both release rate and the magnitude of release at $42{ }^{\circ} \mathrm{C}$ where TSLs containing cholesterol and PEG releases about $50 \%$ over $30 \mathrm{~min}$, while liposomes lacking cholesterol and PEG exhibit a maximum release of $70 \%$ within $10 \mathrm{~min}$. It was found that when $1 \mathrm{~h}$ hyperthermia of 42 or $45^{\circ} \mathrm{C}$ is applied $1 \mathrm{~h}$ after injection TSLs extravasate into interstitial space at the same extent as non-TSLs do, however, using TSLs resulted in 38 and 76-times higher levels of free DXR or CF inside the tumor interstitium upon $1 \mathrm{~h}$ hyperthermia at 42 or $45{ }^{\circ} \mathrm{C}$, respectively [99]. We have shown that for thermoresponsive liposomes a concentration of $5 \mathrm{~mol} \%$ mPEG2000-DSPE is an optimal concentration $[100,101]$, which not only prolongs circulation time of TSLs in blood but also it is believed that the PEG molecules stabilize grain boundaries and facilitate DXR release [102]. We showed that TSLs composed of DPPC:DSPC:mPEG2000-DSPE (80:15:5) quickly release over 70\% of encapsulated $\mathrm{CF}$ at $42{ }^{\circ} \mathrm{C}$ in presence of $100 \%$ serum, while less than $8 \%$ release was observed during $1 \mathrm{~h}$ incubation at $37^{\circ} \mathrm{C}$ in serum. Using intravital imaging we found more than 30 -fold increased DXR level in the heated tumor area compared to free DXR $[100,101]$. Interestingly, this preparation was found to be more effective in treatment of a mouse B16BL6 tumor compared to lysolipid containing TSLs [100].

As discussed earlier one of the goals of triggered drug release is to reduce the reliance of drug delivery on extravasation. To fulfill this, thermosensitive release needs to take place during the short transit time of the liposomes while traveling through the heated area, demanding sharp, fast, and high content release $[103,104]$. Drug molecules released inside the blood while passing through the heated area, i.e., the tumor, have a greater chance to extravasate and distribute inside the tumor. It has been found that intravascular DXR release from liposomes provides deeper penetration and more homogeneous DXR distribution compared to administration of free doxorubicin [103]. In addition to that, intravascular release results in exposure of endothelial cells to high concentration of cytotoxic drug. Uptake of the cytotoxic drug, e.g., DXR, by endothelial cells results in vascular damage and indirectly boosts the treatment efficacy by depriving tumor cells from oxygen and nutrition supply [100] and, in part, contribute to the enhanced antitumor efficacy of TSLs plus hyperthermia $[100,105,106]$.

The great leap in application of thermoresponsive nanoparticles against cancer happened when Needham's group found that incorporation of the lysolipid MPPC drastically increases the rate and magnitude of drug release from DPPC liposomes [107]. The mechanism of this ultra-fast release is related to the tendency of lysolipids to form highly curved micelles. When the temperature approaches the transition temperature of the DPPC membrane, lysolipids find their preferred curvature at the developed grain boundaries in solid-liquid interfaces, and the increased lateral movement at elevated temperature enables them to migrate to the faceted grain structures forming lysolipid-lined nanopores in the lipid bilayer [102]. In fact, both PEG and lysolipids stabilize the grain boundaries resulting in a burst release from nanoporous defects in the lipid bilayer. Lysolipid containing TSLs (LTSLs) composed of DPPC:MPPC:mPEG2000-DSPE (90:10:4 mol ratio) revealed higher therapeutic efficacy compared to non-TSLs or cholesterol containing TSLs when a mild hyperthermia of $42{ }^{\circ} \mathrm{C}$ was applied on the tumor for $1 \mathrm{~h}$ right after injection, and proved to benefit intravascular drug release [108]. However, LTSLs containing MPPC start to release DXR at $36{ }^{\circ} \mathrm{C}$ [108]. Replacing MMPC with MSPC improved the release profile by increasing the onset temperature of release, resulting in more stable liposomes at $37^{\circ} \mathrm{C}[109]$. The outperformance of this formulation in preclinical settings resulted in 
clinical evaluation of LTSLs under the commercial name Thermodox ${ }^{\circledR}[102,104]$, first against liver cancer in combination with radiofrequency ablation (RFA), and for recurrent breast cancer combined with microwave hyperthermia [110].

Inspired by the results obtained with lysolipids the group of Shyh-DarLi used Brij78, a surfactant of C18 conjugated to PEG20 via an ether link, to enhance drug release from DPPC liposomes. The optimized preparation composed of DPPC:Brij78 (96:4 mol\%) and remotely loaded with DXR exhibited comparable thermoresponsive release as was observed with LTSLs [111]. Brij78 not only provides pore formation at grain boundaries to enhance release, the PEG moiety provides steric stabilization. Compared to LTSLs composed of DPPC:MSPC:mPEG2000-DSPE (86:10:4 mol\%), liposomes of DPPC:Brij78 (96:4 mol\%) exhibited similar pharmacokinetics but appeared more effective in an EMT-6 tumor model after a dose of $3 \mathrm{mg}$ DXR/kg and $1 \mathrm{~h}$ hyperthermia of $43^{\circ} \mathrm{C}$ [112]. Later the loading method was changed from $\mathrm{pH}$ gradient to $\mathrm{Cu}^{2+}$ gradient, which improves the pharmacokinetics by a 2.5-times slower clearance rate and 2-times more DXR delivery to the heated tumor compared to LTSLs [113]. However, it should be noted that the most efficient temperature at which Thermodox releases DXR is $41-42{ }^{\circ} \mathrm{C}$ and it has been shown that release at $43{ }^{\circ} \mathrm{C}$ is significantly suppressed by almost $50 \%[102,109]$. Therefore, the lower DXR delivery of LTSLs compared to Brij-TSLs could partly be attributed to overheating of the tumor at $43^{\circ} \mathrm{C}$ in these experiments.

Next to the LTSL another advanced TSL was developed by the Lindner group. They found that addition of 1.2-dipalmitoyl-sn-glycero-3-phosphoglyceroglycerol (DPPGOG or DPPG2, transition temperature $39.7^{\circ} \mathrm{C}$ ), a derivative of the naturally occurring DPPG, into TSLs composed of DPPC:DSPC:DPPGOG (50:20:30 mol\%) results in prolongation of the circulation time of TSLs (t1/2 $9.6 \mathrm{~h}$ in hamsters and $\mathrm{t} 1 / 25.0 \mathrm{~h}$ in rats) and greatly increases the release rate of CF from TSLs in response to mild hyperthermia of $42^{\circ} \mathrm{C}$ [114], which was comparable to the fast release from LTSL composed of DPPC:MPPC:mPEG2000-DSPE (90:10:4 mol ratio). Interestingly, Lindner and coworkers show that DPPGOG-TSLs retained encapsulated CF up to $10 \mathrm{~h}$ at $37^{\circ} \mathrm{C}$ in the presence of $90 \%$ serum, whereas PEG-TSLs and MPPC-LTSLs became unstable after 6 and $3 \mathrm{~h}$ respectively, in the same condition. In addition, DPPGOG-TSLs exhibited $69.7 \pm 1.4 \%$ and $72.8 \pm 1.8 \%$ DXR release during $18 \mathrm{~s}$ at 42 and $43{ }^{\circ} \mathrm{C}$, respectively [115]. However, this has not been compared with MSPC-containing LTSLs. In addition to lipid content, the other parameter that they considered was liposome size. Since they aimed at intravascular release they made liposomes of around $200 \mathrm{~nm}$, which is suitable for long circulating liposome but probably less suitable for extravasation. Two times increase in the diameter of liposomes increases the liposome volume by 8 , which means a $200 \mathrm{~nm}$ liposome is capable of carrying eight times more encapsulated drug compared to a $100 \mathrm{~nm}$ liposome, making it more efficient for intravascular drug release. In addition to preclinical therapeutic efficacy of DXR loaded DPPGOG-TSL + hyperthermia in mouse tumor models, it also showed promising safety and therapeutic benefit when used for treatment advanced feline soft tissue sarcoma [116].

\section{Temperature Sensitive Polymeric Nanoparticles (TSPN)}

Advanced polymerization techniques and the vast compositional space of polymer architectures have stimulated a growing number of studies within the field of responsive polymers. Polymers exhibit the most expansive responsiveness to a variety of chemical, physical, and biological stimuli, including temperature $[117,118]$.

Thermoresponsiveness of polymers results from solubility changes by differing the ambient temperature [118]. Based on the response by increasing the temperature thermoresponsive polymers could be classified into two groups: (a) some thermosensitive polymers are soluble in aqueous medium but their solubility reduces above a critical temperature and are known as polymers exhibiting lower critical solution temperature (LCST). (b) In other thermoresponsive polymers the solubility is reduced below a critical temperature, exhibiting upper critical solution temperature (UCST). Although, both kind of polymers have been used for production of a variety of polymer based thermosensitive nanoparticles, studies on polymers with LCST behavior largely outnumber those on UCST polymers. 
Followed by pioneering works of Heskins and Guillet [119] on poly- $N$-isopropylacrylamide (PNIPAAm), which shed light on the mechanisms underlying thermal behavior of PNIPAAm in aqueous solution or in general other LSCT polymers, this polymer became a backbone in designing thermoresponsive polymers for biomedical applications because it exhibits an LCST around $32{ }^{\circ} \mathrm{C}$, close to physiological temperature [120].

Other polymers such as polyethylene glycol (PEG), poly(propylene glycol) (PPG) [121], poly(glycidyl methyl ether-co-glycidyl ethyl ether) (P(GME-co-GEE)), poly(Nvinylcaprolactam) (PNVCL) and biopolymers such as leucine zipper, collagen, Silk [122] and Elastin-like polypeptides (ELP) [123] have also been used for preparation of thermosensitive drug delivery systems.

In a solution of thermoresponsive polymers the ambient temperature determines how the polymer interacts with water molecules. Below the critical temperature (i.e., LCST), hydrophilic parts of the polymer makes hydrogen bonds with water, as for example in PNIPAAm, the oxygen and nitrogen atoms of amide bond are accepting hydrogen bonds, while the covalently attached hydrogen to the nitrogen atom is a donor of hydrogen bonds, keeping the polymer hydrated as an expanded coil. By increasing the temperature the hydrogen bonds between polymer and water that keep the polymer soluble become weak. Loss of the hydrophilicity imposes restructuring of water molecules surrounding the now hydrophobic polymer which is entropically unfavorable. To compensate this entropic loss of the system water molecules decrease the contact surface with hydrophobic polymers. Water phase out the polymer from the solution and polymer undergoes coil (swollen hydrated state) to globule (shrunken dehydrated state) transition [124,125].

Such transition is suitable to be exploited for triggering release in response to exposure of nanoparticles made of temperature sensitive polymers to heat (Figure $2 b$ ). However, the temperature range at which the particles respond to heat needs to be rationally adjusted. For example, the LCST of the primary and the most studied PNIPAAm homopolymer is around $32{ }^{\circ} \mathrm{C}$, which is below physiological temperature $[124,125]$. As stated earlier, LCST response arises from breaking the hydrophilic interactions of polymer with water. Therefore, addition of hydrophilic moieties to PNIPAAm can simply increase the extent of hydrophilic interactions with water and elevate the LCST. In this regard, many studying groups copolymerized PNIPAAm with hydrophilic monomers such as acrylamide (AAm) in PNIPA-co-AAm [126], acrylic acid (AAc) in PNIPAm-AAc [127], or N-hydroxymethylacrylamide NHMAAM in P-(NIPAAm-co-NHMAAm) [128], and successfully achieved copolymers with higher LCST (Table 1). However, in such systems hyperthermia plays as nanoparticle stabilizer rather than release inducer [126].

In addition to the LCST, critical micellar concentration (CMC) is another parameter that governs the stability of polymeric micelles in an aqueous environment. When micelles are diluted below the CMC, disassembly into unimolecular amphiphiles occurs. Copolymerization with hydrophobic monomers, such as polystyrene (Pst) in PIPAAm-PSt [129], butylmethacrylate (PBMA) in PIPAAm-PBMA [130], poly-L-lactide in P-(IPAAm-co-DMAAm)-b-P-(D,L-lactide), and caprolactone (PCL) in P-(NIPAAm-co-NHMAAm)-b-PCL [128] enhanced the micellar formation and stability of the nanoparticle in aqueous media. In contrast to the addition of hydrophilic monomers that increases the LCST, copolymerization of PNIPAAm with hydrophobic blocks showed no [129-131] or minor [128] effect on the LCST.

By means of copolymerization, choosing the number of repeating units and the molar mass, variety of nanoparticles with desired LCST to sense and release their payload have been fabricated [118]. In a thermoresponsive polymeric nanoparticle the hydrophilic part of a polymer is responsible for the thermosensitivity and also provides a hydrophilic corona around the nanoparticle that enhances circulation life time. Meanwhile, the hydrophobic part determines formation and stability of the particle scaffold, that could be used for incorporation of hydrophobic therapeutics (Table 1). However, the rate of drug release is still the most challenging part that has not yet fulfilled the needs of hyperthermic release at the tumor site. LSCT-based thermoresponsive polymeric nanoparticles exhibit an initial burst release at temperatures below the LSCT and, as can be seen in Table 1, they require prolong duration of 
hyperthermia, few hours to days, to release a significant amount of their payload, which is impractical for clinical use. In addition, for many reported nanoparticles release at $37^{\circ} \mathrm{C}$ is almost identical to what observed at mild hyperthermia. During phase transition, collapse of the soluble thermoresponsive corona and nanoparticle aggregation result in drug release. It should be taken into account that during the phase transition physicochemical characteristics of the hydrophobic core remains intact, thereby the nanoparticle scaffold, which is loaded with drug, does not directly contribute to the drug release, explaining the slow rate of drug release from these nanoparticles. Sun et al. found that increasing the hydrophobicity of the block-copolymer is in favor of doxorubicin (DXR) incorporation into nanoparticles, but at the same time it hampers DXR release from nanoparticles even at temperatures higher than the LCST [132]. In addition to that, formation of a dense shrunken corona, as a result of thermal transition, may also restrict the diffusion of drug from these nanoparticles. Zhang et al. [126] reported a slower release of docetaxel at $43^{\circ} \mathrm{C}$ than at $37^{\circ} \mathrm{C}$, from thermally responsive nanohydrogel, implying the deflation of nanogel porosity and blockage of release. Even more sophisticated structures of supramolecular polymers such as DXR-loaded Cy-PPG nanogels [121], requires $3 \mathrm{~h}$ for $88 \%$ DXR release at $40{ }^{\circ} \mathrm{C}$, or in DXR-loaded PNI-U-DPy micelles (LCST $34{ }^{\circ} \mathrm{C}$ ) after $1 \mathrm{~h}$ at $37{ }^{\circ} \mathrm{C}$ only $10 \%$ of DXR was released [133].

Although the temperature triggered release rate from thermosensitive polymeric nanoparticles does not fit with required drug release rates during applicable hyperthermia treatments, these nanoparticles are successful in induction of thermal triggered cellular interaction and internalization due to increased surface hydrophobicity upon transition [134-138]. Therefore, higher tumor accumulation and higher intracellular internalization of thermoresponsive nanoparticles inside the tumor could be achieved by application of heat. It needs to be taken into account that if surface hydrophobization takes place inside the tumor vasculature, while the intravascular concentration of polymeric nanoparticle is high, it may result in massive aggregation, clotting, and blockage of tumor vessels.

Table 1. Temperature sensitive polymeric nanoparticles fabricated with polymers exhibiting lower critical solution temperature (LCST).

\begin{tabular}{|c|c|c|c|c|c|}
\hline Copolymer & Drug & Size $(\mathrm{nm})$ & LCST & Release Rate & Ref \\
\hline $\begin{array}{c}\text { PNIPAAm-PBMA } \\
\text { poly( } N \text {-isopropylacrylamide- } \\
\text { b-butylmethacrylate })\end{array}$ & Doxorubicin & $338 \pm 23$ & $32.5^{\circ} \mathrm{C}$ & $\begin{array}{l}57 \% \text { after } 5 \mathrm{~h} \text { at } 37^{\circ} \mathrm{C} \\
80 \% \text { after } 5 \mathrm{~h} \text { at } 40^{\circ} \mathrm{C}\end{array}$ & [130] \\
\hline $\begin{array}{l}P \text {-(NIPAAm-co-DMAAm)-b- } P \text {-(D,L-lactide) } \\
\text { poly }(N \text {-isopropylacrylamide-co- } N, N- \\
\text { dimethylacrylamide)-b-poly(D,L-lactide) }\end{array}$ & Doxorubicin & 69.2 & $40^{\circ} \mathrm{C}$ & $\begin{array}{l}2.5 \% \text { after } 4 \text { days at } 37^{\circ} \mathrm{C} \\
11 \% \text { after } 4 \text { days at } 42.5^{\circ} \mathrm{C}\end{array}$ & [139] \\
\hline $\begin{array}{c}\text { PNIPAAm-b-PMMA } \\
\text { poly(N-isopropylacrylamide-b- } \\
\text { methyl methacrylate) }\end{array}$ & $\begin{array}{l}\text { Prednisone } \\
\text { acetate }\end{array}$ & 190 & $33^{\circ} \mathrm{C}$ & $\begin{array}{l}22.5 \% \text { after } 5 \mathrm{~h} \text { at } 27^{\circ} \mathrm{C} \\
\quad 37^{\circ} \mathrm{C} \text { na } \\
50 \% \text { after } 5 \text { h at } 40{ }^{\circ} \mathrm{C}\end{array}$ & [131] \\
\hline $\begin{array}{l}P \text {-(NIPAAm-co-AAm)-b-PDLLA } \\
\text { poly(N-isopropylacrylamide-co- } \\
\text { acrylamide)-b-poly(D,L-lactide })\end{array}$ & Docetaxel & 80 & $40^{\circ} \mathrm{C}$ & $\begin{array}{l}30 \% \text { after } 10 \mathrm{~h} \text { at } 37^{\circ} \mathrm{C} \\
36 \% \text { after } 10 \mathrm{~h} \text { at } 43^{\circ} \mathrm{C}\end{array}$ & [140] \\
\hline $\begin{array}{c}P \text {-(NIPAm-co-AAm) } \\
\text { poly(N-isopropylacrylamide- } \\
\text { co-acrylamide })\end{array}$ & Docetaxel & 50 & $40^{\circ} \mathrm{C}$ & $\begin{array}{l}80 \% \text { after } 50 \mathrm{~h} \text { at } 37^{\circ} \mathrm{C} \\
40 \% \text { after } 50 \mathrm{~h} \text { at } 43^{\circ} \mathrm{C}\end{array}$ & [126] \\
\hline $\begin{array}{c}P \text {-(NIPAAm-co-AAm)-b-PBMA } \\
\text { poly(N-isopropylacrylamide-co- } \\
\text { acrylamide)-b-poly(n-butyl methacrylate) }\end{array}$ & Methotrexate & $175 \pm 15$ & $40^{\circ} \mathrm{C}$ & $\begin{array}{l}21 \% \text { after } 5 \mathrm{~h} \text { at } 37^{\circ} \mathrm{C} \\
53 \% \text { after } 5 \mathrm{~h} \text { at } 42^{\circ} \mathrm{C}\end{array}$ & [141] \\
\hline $\begin{array}{c}P \text {-(NIPAAm-co-NHMAAm)-b-PCL } \\
P-(N, N \text { - isopropylacrylamide-co- } N \text { - } \\
\text { hydroxymethylacrylamide)-b-caprolactone }\end{array}$ & Doxorubicin & $97.2 \pm 20.4$ & $38^{\circ} \mathrm{C}$ & $\begin{array}{l}35 \% \text { after } 25 \mathrm{~h} \text { at } 38^{\circ} \mathrm{C} \\
\mathrm{Na} \text { at } 37 \\
57 \% \text { after } 25 \mathrm{~h} \text { at } 43^{\circ} \mathrm{C}\end{array}$ & [128] \\
\hline $\begin{array}{c}\text { PNI-U-DPy } \\
\text { poly }(N \text {-isopropylacrylamide }) \\
\text { containing pendant U-DPy }\end{array}$ & Doxorubicin & 164 & $34^{\circ} \mathrm{C}$ & $63 \% 2.5$ h 37 & [133] \\
\hline $\begin{array}{c}\text { Cy-functionalized supramolecular } \\
\text { polymer, Cy-PPG }\end{array}$ & Doxorubicin & 76 & $45^{\circ} \mathrm{C}$ & $\begin{array}{l}5 \% \text { after } 2.5 \mathrm{~h} \text { at } 25^{\circ} \mathrm{C} \\
\quad 37^{\circ} \mathrm{C} \text { na } \\
85 \% \text { after } 2.5 \mathrm{~h} \text { at } 40^{\circ} \mathrm{C}\end{array}$ & [121] \\
\hline
\end{tabular}


Table 1. Cont.

\begin{tabular}{|c|c|c|c|c|c|}
\hline Copolymer & Drug & Size (nm) & LCST & Release Rate & Ref \\
\hline $\begin{array}{c}\text { NIPAM-co-AAc } \\
\text { poly(NIPAM-co-acrylic acid) }\end{array}$ & $\begin{array}{l}\text { Doxorubicin } \\
\text { retinoic acid }\end{array}$ & $\begin{array}{l}400 \text { at } 25^{\circ} \mathrm{C} \\
100 \text { at } 37^{\circ} \mathrm{C}\end{array}$ & $37.2^{\circ} \mathrm{C}$ & $\begin{array}{l}40 \% \text { after } 4 \mathrm{~h} \text { at } 37^{\circ} \mathrm{C} \\
80 \% \text { after } 48 \text { h at } 37^{\circ} \mathrm{C}\end{array}$ & [127] \\
\hline $\begin{array}{l}\text { Pentaerythritol polycaprolactone-b- } \\
\text { poly(N-vinylcaprolactam)-Folic acid } \\
\text { (four star-arm PE-PCL-b-PNVCL-FA) }\end{array}$ & Doxorubicin & 185 & $39^{\circ} \mathrm{C}$ & $\begin{array}{l}5 \% \text { after } 5 \mathrm{~h} \text { at } 37^{\circ} \mathrm{C} \\
50 \% \text { after } 5 \mathrm{~h} \text { at } 40^{\circ} \mathrm{C}\end{array}$ & [142] \\
\hline $\begin{array}{c}\text { (cb-P-(HEMA-g-P-(NIPAAm-st-HEAAm)) } \\
\text { cyclic brush poly(2-hydroxyethyl } \\
\text { methacrylate-gpoly }(N- \\
\text { isopropylacrylamide-st- } N \text { - } \\
\text { hydroxyethylacrylamide) })(\mathrm{cb}-P \text { - } \\
\text { (HEMA-g- } P \text {-(NIPAAm-st-HEAAm)) }\end{array}$ & Doxorubicin & 28 & $38^{\circ} \mathrm{C}$ & $\begin{array}{c}28 \% \text { after } 40 \mathrm{~h} \text { at } 25^{\circ} \mathrm{C} \\
32 \% \text { after } 40 \mathrm{~h} \text { at } 37^{\circ} \mathrm{C} \\
52.5 \% \text { after } 40 \mathrm{~h} \text { at } 40^{\circ} \mathrm{C}\end{array}$ & [120] \\
\hline
\end{tabular}

\section{Temperature Sensitive Liposomes Sensitized by Temperature Sensitive Polymers}

Modification of liposome membranes with a temperature sensitive polymer (TSP) goes back to studies of Ringsdorf and coworkers [143], where they incorporated a random copolymer of NIPAM and $N$-[4-(1'-pyrenyl)-butyl]- $N$-n-octadecylacrylamide into a liposome membrane in order to create a model membrane simulating the dynamics of the cytoskeleton to an external stimulus. Later Hoffman [144] conjugated around $4 \mathrm{~mol} \%$ of a phopspholipid into an NIPAM backbone and inserted the thermoresponsive polymer into liposomes, micelles, cell membranes, and hydrophobic interfaces in order to create a thermal control function. However, it was Kano and coworkers that first utilized temperature sensitive polymers to achieve triggered drug release from liposomes in response to heat [145]. It was found that copolymers of NIPAM with octadecyl acrylate (ODA) can sensitize non-TSLs to heat or increase the sensitivity and response of TSLs at elevated temperature. Since then NIPAM based copolymers and a variety of synthetic copolymers of $\mathrm{N}$-(2-hydroxypropyl) methacrylamide (HPMA) [146-148], Poly(acryloylpyrrolidine) (APr) [149,150], (2-ethoxy)ethoxyethyl vinyl ether (EOEOVE) [151-154], as well as biopolymers such as elastin like peptide (ELP) $[138,155,156]$ and zipper peptide $[157,158]$, have been exploited to prepare temperature-sensitive-polymer modified liposomes (TSPLs).

In contrast to thermosensitive polymeric nanoparticles that exhibit a slow rate of drug release in response to heat, TSPLs, in which high amount of free form of drug is encapsulated inside the liposomal reservoir, exhibit faster and more efficient drug release at hyperthermia, which is comparable to what is observed with TSLs. Besides, compared to TSLs, TSPLs exhibit an additional thermal controlled function which is temperature triggered cell interaction [152,159]. Additionally, presence of hydrophilic polymers on the outer surface of liposomes, at temperatures below the LCST of the polymer, is also expected to stabilize the liposome through the steric hindrance effect of hydrated polymer chains both during storage and also upon exposure to the biological milieu. These make TSPLs great candidates for delivering drugs to tumor cells. However, addition of another functional compartment into the liposome vehicle, adds more complexity to the delivery system

In order to decorate liposomes with TSP, the hydrophilic TSP requires a lipophilic unit or units to be incorporated into the hydrophobic core of the lipid membrane and anchor the polymer in the lipid bilayer (Figure 2c). In one approach several anchor units such as ODA $[145,160,161]$, or N,N-didodecylacrylamide (NDDAM) $[162,163]$ could be copolymerized with the polymer as side chains of the polymeric backbone. In another approach a lipophilic unit such as phospholipid [159], 2-dodecyl-sulfanylthiocarbonylsulfanyl-2-methyl propionic acid (DMP) [164], 2 C12 [162,165,166], or cholesterol [147] have been added to the terminal end of the polymer. The hydrophobic modified polymer can then be added to the liposome either through addition to the organic lipid mixture by which both inner and outer membranes of liposomes will contain the thermosensitive polymer (TSP) upon liposome formation, or by post insertion of the copolymer into preformed liposomes by which only the outer surface will be modified. However, Han et al. showed that the hydrophobic isopropyl 
groups of NIPAM can also fix the polymer in a liposome membrane [167,168]. Klemetsrud et al. [169] used electrostatic interaction for modification of positively charged liposomes containing $10 \mathrm{~mol} \%$ DPTAP with the negatively charged NIPAM-co-MAA.

The mechanism by which temperature sensitive polymers trigger drug release from liposomes has not been fully elucidated. Moreover, release varies depending on liposome composition. However, it involves loss of hydrophilicity of the extended polymer chain which moves from a hydrated state at temperatures below the polymer LCST, to the shrunken and dehydrated state of the polymer when the environment temperature has risen above the LCST. Such changes in hydrophilicity and conformational changes have been shown to increase liposomes permeability for the encapsulated drug or may also lead to disintegration of the liposome. The latter is observed in liposomes containing high content of helper lipid dioleoylphosphatidylethanolamine (DOPE), in which thermal response of TSP induces transition of the bilayer liposomal phase into a hexagonal phase, leading to a fast and almost complete disruption of the liposome resulting in payload release (Figure 2c).

Early studies on TSPLs using copolymerized pure NIPAM with about $1 \mathrm{~mol} \%$ ODA showed the capability of NIPAM in promoting drug release from TSLs composed of DPPC, while it failed to induce drug release from EPC liposomes at hyperthermia [145]. Later Kano and coworkers [160] found that NIPAM-ODA on one hand stabilizes liposomes composed of DOPE, which in absence of copolymer cannot form stable liposomes, and on the other hand, sensitizes DOPE liposomes to heat at temperatures close to LCST of the copolymer. However, the LCST of NIPAM at $32{ }^{\circ} \mathrm{C}$ by itself is not practically suitable for hyperthermia application, and copolymerization with hydrophobic ODA moieties results in a broadened endotherm centered at around $30^{\circ} \mathrm{C}$ and once inserted in the liposome membrane drug release starts at temperatures below $30^{\circ} \mathrm{C}[145,160]$. The same release pattern at temperatures below the hyperthermia condition was also observed when liposomes composed of DOPE:EPC (64:36 mol\%) were modified with NIPAM-NDDAM, where about 70\% of encapsulated calcein has been released within $5 \mathrm{~min}$ incubation at $30^{\circ} \mathrm{C}$ [163].

As stated earlier, one solution to adjust the LCST of TSP for hyperthermia treatments at temperatures around $42{ }^{\circ} \mathrm{C}$ is copolymerization of TSP with hydrophilic monomers such as acrylamide (AA). In this regard, Kim et al. [161] found that copolymer of NIPAM with ODA and 2.015 or $3.19 \mathrm{~mol} \%$ AA (P(NIPAM-ODA-AA)) exhibit a sharp coil to globe transition starting at 37 and $43{ }^{\circ} \mathrm{C}$, respectively. Hayashi et al. [164] synthesized a copolymer of NIPAM-NDDAM-AA (86.7:1:12.3 mol\%), which exhibit a cloud point—at which the polymer separates from the solution-at $33.8^{\circ} \mathrm{C}$. When the copolymer was incorporated into liposomes composed of DOPE:EPC (60:40 mol\%) the thermal-triggered calcein release started at $40{ }^{\circ} \mathrm{C}$ and while less than $20 \%$ release observed at $35{ }^{\circ} \mathrm{C}$, around $80 \%$ of encapsulated calcein was released over 5 min incubation at $45^{\circ} \mathrm{C}$. Han et al. [167] modified DXR loaded cholesterol containing TSLs composed of DPPC, HSPC and Chol, (56:28:17 mol\%) with NIPAM-AA (83:17 mol\%, LCST ca $40{ }^{\circ} \mathrm{C}$ ) without using hydrophobic anchor units. Their TSPL released less than $10 \%$ DXR during $5 \mathrm{~min}$ incubation at $37-38^{\circ} \mathrm{C}$, while $65 \%$ release was achieved over 5 min of incubation at $39^{\circ} \mathrm{C}$. In addition to this they found that addition of $3 \%$ mPEG 2000-DSPE into TSPLs improves the stability of these liposomes at $37^{\circ} \mathrm{C}$ in presence of $50 \%$ serum, while this modification does not affect the drug release pattern from the liposomes. Their PEGylated TSPLs showed better therapeutic activity compared to free DXR or TSLs modified with only PEG or NIPAM-AA against B16F10 melanoma tumor model after injection of a DXR dose of $6 \mathrm{mg} / \mathrm{kg}$ followed by $10 \mathrm{~min}$ hyperthermia at $42{ }^{\circ} \mathrm{C}$ applied $1 \mathrm{~h}$ after injection [168].

Ta et al. [164] copolymerized NIPAM with pH sensitive propylacrylic acid (PAA) containing a terminal DMP group to act as anchoring unit $\mathrm{p}$ (NIPAM-PAA)-DMP. Addition of $9 \%$ PAA increases the LCST of NIPAM to $42{ }^{\circ} \mathrm{C}$ at pH 6.5 but decreased the LCST to $28^{\circ} \mathrm{C}$ at pH 5.0, presenting dual function in response to heat and reduced $\mathrm{pH}$. Post insertion of the copolymer into preformed DXR loaded liposomes composed of DPPC, HSPC, Chol, and mPEG 2000-DSPE (54:27:16:3 mol\%) resulted in PEGylated TSPL with less than $10 \%$ DXR leakage after $90 \mathrm{~min}$ incubation at $37^{\circ} \mathrm{C}$ in presence of serum at $\mathrm{pH} 7.5$, but it showed $37 \%$ and $58 \%$ drug release over 3 min hyperthermia of 42 or $43{ }^{\circ} \mathrm{C}$, 
respectively, both at $\mathrm{pH}$ 7.5. Meanwhile, the PEGylated TSPL exhibited about 55\% drug release at $37^{\circ} \mathrm{C}$ at a $\mathrm{pH}$ of 5 mimicking lysosomal condition. They also observed a superior antitumor efficacy of their DXR-loaded PEGylated-PTSL compared to free DXR and the liposomal counterpart without a thermosensitive polymer upon a single injection of $5 \mathrm{mg} / \mathrm{kg}$ DXR into mice bearing B16F10 melanoma tumor followed by a $5 \mathrm{~min}$ hyperthermia $\left(43^{\circ} \mathrm{C}\right)$ applied $6 \mathrm{~h}$ after the iv injection [170].

Mo et al. [148] increased the LCST of NIPAM by copolymerization with hydrophilic $\mathrm{N}$-(2-hydroxypropyl) methacrylamide (HPMA). The copolymer composed of NIPAM:HPMA (94:6 mol\%), and equipped with terminal DMP (p(NIPAM-r-HPMA)-DMP), exhibited an LCST of $42{ }^{\circ} \mathrm{C}$ and once post inserted into DXR-loaded preformed liposomes composed of DPPC, HSPC, Chol, and mPEG2000 (55:25:15:3 mol) in a polymer/lipid mass ratio of 1\%, a sharp release of about 70\% DXR within 1 min was observed, while less than $20 \%$ drug leakage occurred after 60 min incubation at $37^{\circ} \mathrm{C}$. They also showed that the burst release of DXR at hyperthermia resulted in deep penetration of DXR in vitro in tumor spheroids and in vivo in mouse tumors.

Copolymerization of NIPAM with Poly(acryloylpyrrolidine) (Apr), which exhibits transition behavior at temperatures around $50{ }^{\circ} \mathrm{C}$, was also found beneficial to adjust the transition temperature of thermosensitive polymers (TSP) [162].

Kono and coworkers [150,162] modified calcein loaded DOPE liposomes with p(Apr-NIPAM)-2C12 (Apr:NIPAM, 81.6:18.4 mol\%) and achieved $70 \%$ calcein release within $1 \mathrm{~min}$ at $42{ }^{\circ} \mathrm{C}$, while less than $20 \%$ release was observed during $15 \mathrm{~min}$ incubation at $37^{\circ} \mathrm{C}$.

Another TSP with promising results in triggering release from liposomes is (2-ethoxy)ethoxyethyl vinyl ether (EOEOVE), which like NIPAM presents tunable LCST by copolymerization with hydrophilic (increase) or hydrophobic (decrease) comonomers, and was found more effective than NIPAM in sensitizing liposomes to heat [151]. Kono et al. [152] decorated non-thermoresponsive liposomes composed of EYPC:Chol (50:45 mol/mol) with $4 \mathrm{~mol} \% \mathrm{mPEG} 5000-D S P E$ and $2 \mathrm{~mol} \%$ copolymer of EOEOVE-ODVE (MW ca. $18 \mathrm{~K}$ ) and remotely loaded this nanoparticle with DXR. The particle exhibited minor leakage at $37{ }^{\circ} \mathrm{C}, 50 \%$ release at $43{ }^{\circ} \mathrm{C}$, and $90 \%$ release at $45^{\circ} \mathrm{C}$ after 3 min incubation at the indicated temperatures in serum free buffer.

In an extensive in vivo study, they found that these DXR-loaded TSPL are more effective than the liposomal counterpart lacking polymers against a murine c-26 tumor when 10 min hyperthermia of $45^{\circ} \mathrm{C}$ was applied $6 \mathrm{~h}$ after injection [152]. They also showed that the maximum antitumor effect could be obtained when hyperthermia was applied at the moment that intratumoral extravasation-based accumulation of liposomes inside tumor reaches the maximum value [152,153]. For example, application of hyperthermia at $3 \mathrm{~h}$ post injection was less effective than hyperthermia at $12 \mathrm{~h}$ [152].

HPMA polymers are water soluble, biodegradable, and biocompatible polymers that have been extensively used as macromolecular drug carriers due to their long circulation in blood. Hennink and coworkers found that the LCST of HPMA polymers could be tuned by copolymerization of HPMA-monolactate and HPMA-dilactate [171], and investigated the capability of p(HPMA mono/dilactate) equipped with a cholesterol molecule as anchor, in sensitizing liposomes to heat $[146,147]$. They found a significant difference between the transition behavior of HPMA copolymers in solution compared to what was observed when incorporated on lipid membranes. Their optimized copolymer (Mw of $10.0 \mathrm{kDa}$ ), which was suitable for temperature triggered drug release, was composed of monolactate/dilactate ratio of $44 / 56$, and the copolymer solution exhibited a cloud point of $19^{\circ} \mathrm{C}$. However, when $5 \mathrm{~mol} \%$ of copolymer was incorporated into liposomes composed of DOPE:EPC (70:25 mol/mol) the TSPL remained stable at $37^{\circ} \mathrm{C}$, while after $5 \mathrm{~min}$ exposure to HIFU-induced hyperthermia of $45^{\circ} \mathrm{C}$ around $70 \%$ of encapsulated DXR was released [146].

In addition to the synthetic polymers, biopolymers have also attracted considerable attention for drug delivery applications [122]. Among these, elastin like polypeptide was found responsive to heat in a narrow temperature window of less than $2{ }^{\circ} \mathrm{C}$ [172]. Park et al. [156] synthesized a peptide composed of three repeats of VPGVG amino acids, conjugated to a stearyl group (C18) at $N$-terminus, and amidized the C-terminal (SA-ELP3-NH2). Incorporation of $1 \mathrm{~mol} \%$ of this lipopeptide into 
liposomes composed of DPPC:Chol:mPEG2000-DSPE (76:21:3 mol\%) and loaded with DXR resulted in a fast drug release at mild hyperthermia of $42{ }^{\circ} \mathrm{C}$ with $\geq 95 \%$ release within $10 \mathrm{~s}$ in the presence of $20 \%$ serum, comparable to what was observed with LTSL composed of DPPC:DMPC:mPEG2000-DSPE (90:10:4 mol\%). However, compared to LTSL these nanocarriers showed 3-times more leakage stability at $37^{\circ} \mathrm{C}$, exhibited 2-times longer blood circulation half-life after single i.v. injection of $5 \mathrm{mg} \mathrm{DXR} / \mathrm{kg}$ into BALB/c mice, and finally showed greater antitumor response against a SCC-7 tumor model at a dose of $5 \mathrm{mg}$ DXR $/ \mathrm{kg}$ when $1 \mathrm{~h}$ hyperthermia of $43^{\circ} \mathrm{C}$ was applied after the injection.

As stated earlier, addition of functional copolymers into liposomes adds more complexity to the delivery system. So far, a variety of liposomes with different lipid composition have been modified with a variety of copolymers with different chemistry. In fact, most of these studies mainly focused on proving the concept or applicability of such designed system rather than on formulation optimization in order to improve therapeutic activity and performance. Lack of such experimental evidence makes it impossible to discuss in-depth about TSPL, or to correlate or compare the activity of different preparations. Here we provide some insights in the concept, mechanism of drug release, methods of liposome modification, and rationale of copolymer modifications. Additionally, different TSPLs have been introduced concisely while the most critical features of these studies, including formulation details, experimental setting and results, are presented.

\section{Conclusions}

A variety of nanoparticles with thermally triggered drug release profile have been produced and studied in different preclinical settings. Different from polymeric nanoparticles, which require impractical long duration of heating to release significant amount of drug, liposome-based temperature sensitive nanoparticles show more promising results. So far, the most advanced systems are thermosensitive liposomes, with super-fast drug release that should reach complete drug release during passage through the heated area (i.e., the tumor). Next to the capabilities of nanoparticles to deliver and release a payload at the heated area, timing, duration, and degree of hyperthermia are also crucially important parameters. Lessons learned during almost four decades, and more importantly failure of clinical trials, reveal that this combination could be successful when mild hyperthermia $\left(40-42{ }^{\circ} \mathrm{C}\right)$ is applied for 30-60 min (when blood level of nanoparticles is still high) started concomitantly or prior to nanoparticle injection. While temperatures in the range of $40-42{ }^{\circ} \mathrm{C}$ are tolerated well by patients, application of higher temperatures $\left(\geq 43^{\circ} \mathrm{C}\right)$ not only results in patient discomfort but also hampers drug delivery due to the possibility of vascular collapse. Therefore, it is important to optimize temperature sensitive nanoparticle with regards to these conditions. For example, one may think it is possible to adjust heat deposition to a safe thermal dose while using a high temperature, which would be necessary for fast and complete release from nanoparticles acting at a temperature above $42{ }^{\circ} \mathrm{C}$, by decreasing the hyperthermia duration. However, in such setting, in an intravascular drug release treatment, the overall drug delivery is still impaired because only a portion of the administered nanoparticles are being exposed to heat. If extravascular drug release is aimed, it is not rational to overheat the tumor as fast drug release from extravasated nanoparticles is not really beneficial whereas a sustained drug release may likely favor intratumoral drug distribution

Author Contributions: M.A., W.H. and A.L.B.S. wrote the manuscript; T.L.M.t.H. supervised, reviewed and edited the work. All authors have read and agreed to the published version of the manuscript.

Funding: This work was supported in part by the research program of the National Institutes of Health; NIH grant R01CA181664 (MA, TLMtH)-R01 CA181664/CA/NCI NIH HHS/United States.

Acknowledgments: The authors thank A.M.J. ten Hagen of Nomena for help with the figure.

Conflicts of Interest: The authors declare no conflict of interest. 


\section{References}

1. Kieler-Ferguson, H.M.; Frechet, J.M.; Szoka, F.C., Jr. Clinical developments of chemotherapeutic nanomedicines: Polymers and liposomes for delivery of camptothecins and platinum (ii) drugs. Wiley Interdiscip. Rev. Nanomed. Nanobiotechnol. 2013, 5, 130-138. [CrossRef]

2. Powis, G. Dose-dependent metabolism, therapeutic effect, and toxicity of anticancer drugs in man. Drug Metab. Rev. 1983, 14, 1145-1163. [CrossRef]

3. Bhakay, A.; Rahman, M.; Dave, R.N.; Bilgili, E. Bioavailability enhancement of poorly water-soluble drugs via nanocomposites: Formulation(-)processing aspects and challenges. Pharmaceutics 2018, 10, 86. [CrossRef]

4. Kalepu, S.; Nekkanti, V. Insoluble drug delivery strategies: Review of recent advances and business prospects. Acta Pharm. Sin. B 2015, 5, 442-453. [CrossRef]

5. Picard, M.; Castells, M.C. Re-visiting hypersensitivity reactions to taxanes: A comprehensive review. Clin. Rev. Allergy Immunol. 2015, 49, 177-191. [CrossRef]

6. Passero, F.C., Jr.; Grapsa, D.; Syrigos, K.N.; Saif, M.W. The safety and efficacy of onivyde (irinotecan liposome injection) for the treatment of metastatic pancreatic cancer following gemcitabine-based therapy. Expert Rev. Anticancer Ther. 2016, 16, 697-703. [CrossRef]

7. Zhang, H. Onivyde for the therapy of multiple solid tumors. Onco Targets Ther. 2016, 9, 3001-3007. [CrossRef]

8. Lamb, Y.N.; Scott, L.J. Liposomal irinotecan: A review in metastatic pancreatic adenocarcinoma. Drugs 2017, 77, 785-792. [CrossRef]

9. Papahadjopoulos, D.; Allen, T.M.; Gabizon, A.; Mayhew, E.; Matthay, K.; Huang, S.K.; Lee, K.D.; Woodle, M.C.; Lasic, D.D.; Redemann, C.; et al. Sterically stabilized liposomes: Improvements in pharmacokinetics and antitumor therapeutic efficacy. Proc. Natl. Acad. Sci. USA 1991, 88, 11460-11464. [CrossRef]

10. Matsumura, Y.; Maeda, H. A new concept for macromolecular therapeutics in cancer chemotherapy: Mechanism of tumoritropic accumulation of proteins and the antitumor agent smancs. Cancer Res. 1986, 46, 6387-6392.

11. Golombek, S.K.; May, J.N.; Theek, B.; Appold, L.; Drude, N.; Kiessling, F.; Lammers, T. Tumor targeting via epr: Strategies to enhance patient responses. Adv. Drug Deliv. Rev. 2018, 130, 17-38. [CrossRef]

12. Gabizon, A.; Shmeeda, H.; Barenholz, Y. Pharmacokinetics of pegylated liposomal doxorubicin: Review of animal and human studies. Clin. Pharm. 2003, 42, 419-436. [CrossRef]

13. Barenholz, Y. Doxil(r)—The first fda-approved nano-drug: Lessons learned. J. Control. Release 2012, 160, 117-134. [CrossRef]

14. Northfelt, D.W.; Martin, F.J.; Working, P.; Volberding, P.A.; Russell, J.; Newman, M.; Amantea, M.A.; Kaplan, L.D. Doxorubicin encapsulated in liposomes containing surface-bound polyethylene glycol: Pharmacokinetics, tumor localization, and safety in patients with aids-related kaposi's sarcoma. J. Clin. Pharmacol. 1996, 36, 55-63. [CrossRef]

15. Udhrain, A.; Skubitz, K.M.; Northfelt, D.W. Pegylated liposomal doxorubicin in the treatment of aids-related kaposi's sarcoma. Int. J. Nanomed. 2007, 2, 345-352.

16. Symon, Z.; Peyser, A.; Tzemach, D.; Lyass, O.; Sucher, E.; Shezen, E.; Gabizon, A. Selective delivery of doxorubicin to patients with breast carcinoma metastases by stealth liposomes. Cancer 1999, 86, 72-78. [CrossRef]

17. Harrington, K.J.; Mohammadtaghi, S.; Uster, P.S.; Glass, D.; Peters, A.M.; Vile, R.G.; Stewart, J.S. Effective targeting of solid tumors in patients with locally advanced cancers by radiolabeled pegylated liposomes. Clin. Cancer Res. 2001, 7, 243-254.

18. Primeau, A.J.; Rendon, A.; Hedley, D.; Lilge, L.; Tannock, I.F. The distribution of the anticancer drug doxorubicin in relation to blood vessels in solid tumors. Clin. Cancer Res. 2005, 11, 8782-8788. [CrossRef]

19. Teicher, B.A.; Ara, G.; Keyes, S.R.; Herbst, R.S.; Frei, E., 3rd. Acute in vivo resistance in high-dose therapy. Clin. Cancer Res. 1998, 4, 483-491.

20. Larsen, A.K.; Escargueil, A.E.; Skladanowski, A. Resistance mechanisms associated with altered intracellular distribution of anticancer agents. Pharmacol. Ther. 2000, 85, 217-229. [CrossRef]

21. Gartung, A.; Yang, J.; Sukhatme, V.P.; Bielenberg, D.R.; Fernandes, D.; Chang, J.; Schmidt, B.A.; Hwang, S.H.; Zurakowski, D.; Huang, S.; et al. Suppression of chemotherapy-induced cytokine/lipid mediator surge and ovarian cancer by a dual cox-2/seh inhibitor. Proc. Natl. Acad. Sci. USA 2019, 116, 1698-1703. [CrossRef] 
22. Chang, J.; Bhasin, S.S.; Bielenberg, D.R.; Sukhatme, V.P.; Bhasin, M.; Huang, S.; Kieran, M.W.; Panigrahy, D. Chemotherapy-generated cell debris stimulates colon carcinoma tumor growth via osteopontin. FASEB J. 2019, 33, 114-125. [CrossRef]

23. Seelig, K.J.; Revesz, L. Effect of lethally damaged tumour cells upon the growth of admixed viable cells in diffusion chambers. Br. J. Cancer 1960, 14, 126-138. [CrossRef]

24. Tan, Q.; Saggar, J.K.; Yu, M.; Wang, M.; Tannock, I.F. Mechanisms of drug resistance related to the microenvironment of solid tumors and possible strategies to inhibit them. Cancer J. 2015, 21, 254-262. [CrossRef]

25. Minchinton, A.I.; Tannock, I.F. Drug penetration in solid tumours. Nat. Rev. Cancer 2006, 6, 583-592. [CrossRef]

26. Chauhan, V.P.; Stylianopoulos, T.; Martin, J.D.; Popovic, Z.; Chen, O.; Kamoun, W.S.; Bawendi, M.G.; Fukumura, D.; Jain, R.K. Normalization of tumour blood vessels improves the delivery of nanomedicines in a size-dependent manner. Nat. Nanotechnol. 2012, 7, 383-388. [CrossRef]

27. Tong, R.T.; Boucher, Y.; Kozin, S.V.; Winkler, F.; Hicklin, D.J.; Jain, R.K. Vascular normalization by vascular endothelial growth factor receptor 2 blockade induces a pressure gradient across the vasculature and improves drug penetration in tumors. Cancer Res. 2004, 64, 3731-3736. [CrossRef]

28. Winkler, F.; Kozin, S.V.; Tong, R.T.; Chae, S.S.; Booth, M.F.; Garkavtsev, I.; Xu, L.; Hicklin, D.J.; Fukumura, D.; di Tomaso, E.; et al. Kinetics of vascular normalization by vegfr2 blockade governs brain tumor response to radiation: Role of oxygenation, angiopoietin-1, and matrix metalloproteinases. Cancer Cell 2004, 6, 553-563.

29. Zhang, B.; Shi, W.; Jiang, T.; Wang, L.; Mei, H.; Lu, H.; Hu, Y.; Pang, Z. Optimization of the tumor microenvironment and nanomedicine properties simultaneously to improve tumor therapy. Oncotarget 2016, 7, 62607-62618. [CrossRef]

30. Diop-Frimpong, B.; Chauhan, V.P.; Krane, S.; Boucher, Y.; Jain, R.K. Losartan inhibits collagen i synthesis and improves the distribution and efficacy of nanotherapeutics in tumors. Proc. Natl. Acad. Sci. USA 2011, 108, 2909-2914. [CrossRef]

31. Seynhaeve, A.L.; Dicheva, B.M.; Hoving, S.; Koning, G.A.; Ten Hagen, T.L. Intact doxil is taken up intracellularly and released doxorubicin sequesters in the lysosome: Evaluated by in vitro/in vivo live cell imaging. J. Control. Release 2013, 172, 330-340. [CrossRef]

32. Seynhaeve, A.L.; Hoving, S.; Schipper, D.; Vermeulen, C.E.; de Wiel-Ambagtsheer, G.; van Tiel, S.T.; Eggermont, A.M.; Ten Hagen, T.L. Tumor necrosis factor alpha mediates homogeneous distribution of liposomes in murine melanoma that contributes to a better tumor response. Cancer Res. 2007, 67, 9455-9462. [CrossRef]

33. Jain, R.K.; Stylianopoulos, T. Delivering nanomedicine to solid tumors. Nat. Rev. Clin. Oncol. 2010, 7, 653-664. [CrossRef]

34. Seynhaeve, A.L.B.; Amin, M.; Haemmerich, D.; van Rhoon, G.C.; Ten Hagen, T.L.M. Hyperthermia and smart drug delivery systems for solid tumor therapy. Adv. Drug Deliv. Rev. 2020. [CrossRef]

35. El Emir, E.; Qureshi, U.; Dearling, J.L.; Boxer, G.M.; Clatworthy, I.; Folarin, A.A.; Robson, M.P.; Nagl, S.; Konerding, M.A.; Pedley, R.B. Predicting response to radioimmunotherapy from the tumor microenvironment of colorectal carcinomas. Cancer Res. 2007, 67, 11896-11905. [CrossRef]

36. Lee, H.; Shields, A.F.; Siegel, B.A.; Miller, K.D.; Krop, I.; Ma, C.X.; LoRusso, P.M.; Munster, P.N.; Campbell, K.; Gaddy, D.F.; et al. (64)cu-mm-302 positron emission tomography quantifies variability of enhanced permeability and retention of nanoparticles in relation to treatment response in patients with metastatic breast cancer. Clin. Cancer Res. 2017, 23, 4190-4202. [CrossRef]

37. Eberhard, A.; Kahlert, S.; Goede, V.; Hemmerlein, B.; Plate, K.H.; Augustin, H.G. Heterogeneity of angiogenesis and blood vessel maturation in human tumors: Implications for antiangiogenic tumor therapies. Cancer Res. 2000, 60, 1388-1393.

38. Matsumoto, Y.; Nichols, J.W.; Toh, K.; Nomoto, T.; Cabral, H.; Miura, Y.; Christie, R.J.; Yamada, N.; Ogura, T.; Kano, M.R.; et al. Vascular bursts enhance permeability of tumour blood vessels and improve nanoparticle delivery. Nat. Nanotechnol. 2016, 11, 533-538. [CrossRef]

39. Sindhwani, S.; Syed, A.M.; Ngai, J.; Kingston, B.R.; Maiorino, L.; Rothschild, J.; MacMillan, P.; Zhang, Y.; Rajesh, N.U.; Hoang, T.; et al. The entry of nanoparticles into solid tumours. Nat. Mater. 2020, 19, 566-575. [CrossRef] 
40. Gaber, M.H.; Wu, N.Z.; Hong, K.; Huang, S.K.; Dewhirst, M.W.; Papahadjopoulos, D. Thermosensitive liposomes: Extravasation and release of contents in tumor microvascular networks. Int. J. Radiat. Oncol. Biol. Phys. 1996, 36, 1177-1187. [CrossRef]

41. Amin, M.; Bagheri, M.; Mansourian, M.; Jaafari, M.R.; Ten Hagen, T.L. Regulation of in vivo behavior of tat-modified liposome by associated protein corona and avidity to tumor cells. Int. J. Nanomed. 2018, 13, 7441-7455. [CrossRef]

42. Seetharamu, N.; Kim, E.; Hochster, H.; Martin, F.; Muggia, F. Phase ii study of liposomal cisplatin (spi-77) in platinum-sensitive recurrences of ovarian cancer. Anticancer Res. 2010, 30, 541-545.

43. Amin, M.; Badiee, A.; Jaafari, M.R. Improvement of pharmacokinetic and antitumor activity of pegylated liposomal doxorubicin by targeting with n-methylated cyclic rgd peptide in mice bearing c-26 colon carcinomas. Int. J. Pharm. 2013, 458, 324-333. [CrossRef]

44. Allen, T.M.; Cullis, P.R. Liposomal drug delivery systems: From concept to clinical applications. Adv. Drug Deliv. Rev. 2013, 65, 36-48. [CrossRef]

45. van der Meel, R.; Vehmeijer, L.J.; Kok, R.J.; Storm, G.; van Gaal, E.V. Ligand-targeted particulate nanomedicines undergoing clinical evaluation: Current status. Adv. Drug Deliv. Rev. 2013, 65, 1284-1298. [CrossRef]

46. Lee, E.S.; Gao, Z.; Bae, Y.H. Recent progress in tumor ph targeting nanotechnology. J. Control. Release 2008, 132, 164-170. [CrossRef]

47. Yatvin, M.B.; Kreutz, W.; Horwitz, B.A.; Shinitzky, M. Ph-sensitive liposomes: Possible clinical implications. Science 1980, 210, 1253-1255. [CrossRef]

48. Andresen, T.L.; Thompson, D.H.; Kaasgaard, T. Enzyme-triggered nanomedicine: Drug release strategies in cancer therapy. Mol. Membr. Biol. 2010, 27, 353-363. [CrossRef]

49. Ong, W.; Yang, Y.; Cruciano, A.C.; McCarley, R.L. Redox-triggered contents release from liposomes. J. Am. Chem. Soc. 2008, 130, 14739-14744. [CrossRef]

50. Wang, C.; Qi, P.; Lu, Y.; Liu, L.; Zhang, Y.; Sheng, Q.; Wang, T.; Zhang, M.; Wang, R.; Song, S. Bicomponent polymeric micelles for ph-controlled delivery of doxorubicin. Drug Deliv. 2020, 27, 344-357. [CrossRef]

51. Jin, Z.H.; Jin, M.J.; Jiang, C.G.; Yin, X.Z.; Jin, S.X.; Quan, X.Q.; Gao, Z.G. Evaluation of doxorubicin-loaded ph-sensitive polymeric micelle release from tumor blood vessels and anticancer efficacy using a dorsal skin-fold window chamber model. Acta Pharmacol. Sin. 2014, 35, 839-845. [CrossRef]

52. Xu, Y.; Zhang, J.; Liu, X.; Huo, P.; Zhang, Y.; Chen, H.; Tian, Q.; Zhang, N. Mmp-2-responsive gelatin nanoparticles for synergistic tumor therapy. Pharm. Dev. Technol. 2019, 24, 1002-1013. [CrossRef]

53. Jiang, J.; Shen, N.; Ci, T.; Tang, Z.; Gu, Z.; Li, G.; Chen, X. Combretastatin a4 nanodrug-induced mmp9 amplification boosts tumor-selective release of doxorubicin prodrug. Adv. Mater. 2019, 31, e1904278. [CrossRef]

54. Nagel, G.; Sousa-Herves, A.; Wedepohl, S.; Calderon, M. Matrix metalloproteinase-sensitive multistage nanogels promote drug transport in $3 \mathrm{~d}$ tumor model. Theranostics 2020, 10, 91-108. [CrossRef]

55. Mo, S.; Coussios, C.C.; Seymour, L.; Carlisle, R. Ultrasound-enhanced drug delivery for cancer. Expert Opin. Drug Deliv. 2012, 9, 1525-1538. [CrossRef]

56. Eggen, S.; Fagerland, S.M.; Morch, Y.; Hansen, R.; Sovik, K.; Berg, S.; Furu, H.; Bohn, A.D.; Lilledahl, M.B.; Angelsen, A.; et al. Ultrasound-enhanced drug delivery in prostate cancer xenografts by nanoparticles stabilizing microbubbles. J. Control. Release 2014, 187, 39-49. [CrossRef]

57. Huang, S.L. Liposomes in ultrasonic drug and gene delivery. Adv. Drug Deliv. Rev. 2008, 60, 1167-1176. [CrossRef]

58. Leung, S.J.; Romanowski, M. Light-activated content release from liposomes. Theranostics 2012, 2, $1020-1036$. [CrossRef]

59. Bansal, A.; Zhang, Y. Photocontrolled nanoparticle delivery systems for biomedical applications. Acc. Chem. Res. 2014, 47, 3052-3060. [CrossRef]

60. Mura, S.; Nicolas, J.; Couvreur, P. Stimuli-responsive nanocarriers for drug delivery. Nat. Mater. 2013, 12, 991-1003. [CrossRef]

61. Senapati, S.; Mahanta, A.K.; Kumar, S.; Maiti, P. Controlled drug delivery vehicles for cancer treatment and their performance. Signal Transduct. Target. Ther. 2018, 3, 7. [CrossRef]

62. Nittayacharn, P.; Yuan, H.X.; Hernandez, C.; Bielecki, P.; Zhou, H.; Exner, A.A. Enhancing tumor drug distribution with ultrasound-triggered nanobubbles. J. Pharm. Sci. 2019, 108, 3091-3098. [CrossRef] 
63. Rizzitelli, S.; Giustetto, P.; Cutrin, J.C.; Delli Castelli, D.; Boffa, C.; Ruzza, M.; Menchise, V.; Molinari, F.; Aime, S.; Terreno, E. Sonosensitive theranostic liposomes for preclinical in vivo mri-guided visualization of doxorubicin release stimulated by pulsed low intensity non-focused ultrasound. J. Control. Release 2015, 202, 21-30. [CrossRef]

64. Li, L.; Ten Hagen, T.L.; Bolkestein, M.; Gasselhuber, A.; Yatvin, J.; van Rhoon, G.C.; Eggermont, A.M.; Haemmerich, D.; Koning, G.A. Improved intratumoral nanoparticle extravasation and penetration by mild hyperthermia. J. Control. Release 2013, 167, 130-137. [CrossRef]

65. Lu, T.; Lokerse, W.J.M.; Seynhaeve, A.L.B.; Koning, G.A.; Ten Hagen, T.L.M. Formulation and optimization of idarubicin thermosensitive liposomes provides ultrafast triggered release at mild hyperthermia and improves tumor response. J. Control. Release 2015, 220, 425-437. [CrossRef]

66. Gas, P. Essential facts on the history of hyperthermia and their connections with electromedicine. Prz Elektrotechniczn 2011, 87, 37-40.

67. Lepock, J.R. Cellular effects of hyperthermia: Relevance to the minimum dose for thermal damage. Int. J. Hyperther. 2003, 19, 252-266. [CrossRef]

68. Roti, J.L.R. Cellular responses to hyperthermia $\left(40-46{ }^{\circ} \mathrm{C}\right)$ : Cell killing and molecular events. Int. J. Hyperther. 2008, 24, 3-15. [CrossRef]

69. Overgaard, J.; Grau, C.; Lindegaard, J.C.; Horsman, M.R. The potential of using hyperthermia to eliminate radioresistant hypoxic cells. Radiother. Oncol. 1991, 20, 113-116. [CrossRef]

70. Oei, A.L.; Vriend, L.E.M.; Crezee, J.; Franken, N.A.P.; Krawczyk, P.M. Effects of hyperthermia on DNA repair pathways: One treatment to inhibit them all. Radiat. Oncol. 2015, 10, 1-13. [CrossRef]

71. Griffin, R.J.; Ogawa, A.; Williams, B.W.; Song, C.W. Hyperthermic enhancement of tumor radiosensitization strategies. Immunol. Investig. 2005, 34, 343-359. [CrossRef]

72. Griffin, R.J.; Dings, R.P.; Jamshidi-Parsian, A.; Song, C.W. Mild temperature hyperthermia and radiation therapy: Role of tumour vascular thermotolerance and relevant physiological factors. Int. J. Hyperth. 2010, 26, 256-263. [CrossRef]

73. Skitzki, J.J.; Repasky, E.A.; Evans, S.S. Hyperthermia as an immunotherapy strategy for cancer. Curr. Opin. Investig. Drugs 2009, 10, 550-558.

74. Lee, S.; Son, B.; Park, G.; Kim, H.; Kang, H.; Jeon, J.; Youn, H.; Youn, B. Immunogenic effect of hyperthermia on enhancing radiotherapeutic efficacy. Int. J. Mol. Sci. 2018, 19, 2795. [CrossRef]

75. Toraya-Brown, S.; Sheen, M.R.; Zhang, P.; Chen, L.; Baird, J.R.; Demidenko, E.; Turk, M.J.; Hoopes, P.J.; Conejo-Garcia, J.R.; Fiering, S. Local hyperthermia treatment of tumors induces cd8(+) $t$ cell-mediated resistance against distal and secondary tumors. Nanomedicine 2014, 10, 1273-1285. [CrossRef]

76. Tsang, Y.W.; Huang, C.C.; Yang, K.L.; Chi, M.S.; Chiang, H.C.; Wang, Y.S.; Andocs, G.; Szasz, A.; Li, W.T.; Chi, K.H. Improving immunological tumor microenvironment using electro-hyperthermia followed by dendritic cell immunotherapy. BMC Cancer 2015, 15, 1-11. [CrossRef]

77. Binder, R.J.; Han, D.K.; Srivastava, P.K. Cd91: A receptor for heat shock protein gp96. Nat. Immunol. 2000, 1, 151-155. [CrossRef]

78. Bethke, K.; Staib, F.; Distler, M.; Schmitt, U.; Jonuleit, H.; Enk, A.H.; Galle, P.R.; Heike, M. Different efficiency of heat shock proteins (hsp) to activate human monocytes and dendritic cells: Superiority of hsp60. J. Immunol. 2002, 169, 6141-6148. [CrossRef]

79. Todryk, S.; Melcher, A.A.; Hardwick, N.; Linardakis, E.; Bateman, A.; Colombo, M.P.; Stoppacciaro, A.; Vile, R.G. Heat shock protein 70 induced during tumor cell killing induces th1 cytokines and targets immature dendritic cell precursors to enhance antigen uptake. J. Immunol. 1999, 163, 1398-1408.

80. Issels, R.D.; Lindner, L.H.; Verweij, J.; Wust, P.; Reichardt, P.; Schem, B.C.; Abdel-Rahman, S.; Daugaard, S.; Salat, C.; Wendtner, C.M.; et al. Neo-adjuvant chemotherapy alone or with regional hyperthermia for localised high-risk soft-tissue sarcoma: A randomised phase 3 multicentre study. Lancet Oncol. 2010, 11, 561-570. [CrossRef]

81. Issels, R.D.; Lindner, L.H.; Verweij, J.; Wessalowski, R.; Reichardt, P.; Wust, P.; Ghadjar, P.; Hohenberger, P.; Angele, M.; Salat, C.; et al. Effect of neoadjuvant chemotherapy plus regional hyperthermia on long-term outcomes among patients with localized high-risk soft tissue sarcoma: The eortc 62961-esho 95 randomized clinical trial. JAMA Oncol. 2018, 4, 483-492. [CrossRef]

82. Killock, D. Sarcoma: Local hyperthermia improves survival. Nat. Rev. Clin. Oncol. 2018, 15, 266. [CrossRef] 
83. Huang, S.K.; Stauffer, P.R.; Hong, K.; Guo, J.W.; Phillips, T.L.; Huang, A.; Papahadjopoulos, D. Liposomes and hyperthermia in mice: Increased tumor uptake and therapeutic efficacy of doxorubicin in sterically stabilized liposomes. Cancer Res. 1994, 54, 2186-2191.

84. Kong, G.; Braun, R.D.; Dewhirst, M.W. Hyperthermia enables tumor-specific nanoparticle delivery: Effect of particle size. Cancer Res. 2000, 60, 4440-4445.

85. Kong, G.; Braun, R.D.; Dewhirst, M.W. Characterization of the effect of hyperthermia on nanoparticle extravasation from tumor vasculature. Cancer Res. 2001, 61, 3027-3032.

86. Ponce, A.M.; Viglianti, B.L.; Yu, D.; Yarmolenko, P.S.; Michelich, C.R.; Woo, J.; Bally, M.B.; Dewhirst, M.W. Magnetic resonance imaging of temperature-sensitive liposome release: Drug dose painting and antitumor effects. J. Natl. Cancer Inst. 2007, 99, 53-63. [CrossRef]

87. Stapleton, S.; Dunne, M.; Milosevic, M.; Tran, C.W.; Gold, M.J.; Vedadi, A.; McKee, T.D.; Ohashi, P.S.; Allen, C.; Jaffray, D.A. Radiation and heat improve the delivery and efficacy of nanotherapeutics by modulating intratumoral fluid dynamics. ACS Nano 2018, 12, 7583-7600. [CrossRef]

88. Eze, M.O. Phase-transitions in phospholipid-bilayers-Lateral phase separations play vital roles in biomembranes. Biochem. Educ. 1991, 19, 204-208. [CrossRef]

89. Marsh, D. General features of phospholipid phase-transitions. Chem. Phys. Lipids 1991, 57, $109-120$. [CrossRef]

90. Papahadjopoulos, D.; Jacobson, K.; Nir, S.; Isac, T. Phase transitions in phospholipid vesicles. Fluorescence polarization and permeability measurements concerning the effect of temperature and cholesterol. Biochim. Biophys. Acta 1973, 311, 330-348. [CrossRef]

91. Lu, T.; Ten Hagen, T.L.M. Inhomogeneous crystal grain formation in dppc-dspc based thermosensitive liposomes determines content release kinetics. J. Control. Release 2017, 247, 64-72. [CrossRef]

92. Phillips, M.C.; Hauser, H.; Paltauf, F. The inter- and intra-molecular mixing of hydrocarbon chains in lecithin-water systems. Chem. Phys. Lipids 1972, 8, 127-133. [CrossRef]

93. Yatvin, M.B.; Weinstein, J.N.; Dennis, W.H.; Blumenthal, R. Design of liposomes for enhanced local release of drugs by hyperthermia. Science 1978, 202, 1290-1293. [CrossRef]

94. Weinstein, J.N.; Magin, R.L.; Yatvin, M.B.; Zaharko, D.S. Liposomes and local hyperthermia: Selective delivery of methotrexate to heated tumors. Science 1979, 204, 188-191. [CrossRef]

95. Yatvin, M.B.; Muhlensiepen, H.; Porschen, W.; Weinstein, J.N.; Feinendegen, L.E. Selective delivery of liposome-associated cis-dichlorodiammineplatinum(ii) by heat and its influence on tumor drug uptake and growth. Cancer Res. 1981, 41, 1602-1607.

96. Iga, K.; Hamaguchi, N.; Igari, Y.; Ogawa, Y.; Gotoh, K.; Ootsu, K.; Toguchi, H.; Shimamoto, T. Enhanced antitumor activity in mice after administration of thermosensitive liposome encapsulating cisplatin with hyperthermia. J. Pharmacol. Exp. Ther. 1991, 257, 1203-1207.

97. Maruyama, K.; Unezaki, S.; Takahashi, N.; Iwatsuru, M. Enhanced delivery of doxorubicin to tumor by long-circulating thermosensitive liposomes and local hyperthermia. Biochim. Biophys. Acta 1993, 1149, 209-216. [CrossRef]

98. Gaber, M.H.; Hong, K.; Huang, S.K.; Papahadjopoulos, D. Thermosensitive sterically stabilized liposomes: Formulation and in vitro studies on mechanism of doxorubicin release by bovine serum and human plasma. Pharm. Res. 1995, 12, 1407-1416. [CrossRef]

99. Lokerse, W.J.; Kneepkens, E.C.; ten Hagen, T.L.; Eggermont, A.M.; Grull, H.; Koning, G.A. In depth study on thermosensitive liposomes: Optimizing formulations for tumor specific therapy and in vitro to in vivo relations. Biomaterials 2016, 82, 138-150. [CrossRef]

100. Li, L.; ten Hagen, T.L.; Hossann, M.; Suss, R.; van Rhoon, G.C.; Eggermont, A.M.; Haemmerich, D.; Koning, G.A. Mild hyperthermia triggered doxorubicin release from optimized stealth thermosensitive liposomes improves intratumoral drug delivery and efficacy. J. Control. Release 2013, 168, 142-150. [CrossRef]

101. Li, L.; ten Hagen, T.L.; Schipper, D.; Wijnberg, T.M.; van Rhoon, G.C.; Eggermont, A.M.; Lindner, L.H.; Koning, G.A. Triggered content release from optimized stealth thermosensitive liposomes using mild hyperthermia. J. Control. Release 2010, 143, 274-279. [CrossRef]

102. Landon, C.D.; Park, J.Y.; Needham, D.; Dewhirst, M.W. Nanoscale drug delivery and hyperthermia: The materials design and preclinical and clinical testing of low temperature-sensitive liposomes used in combination with mild hyperthermia in the treatment of local cancer. Open Nanomed. J. 2011, 3, 38-64. [CrossRef] 
103. Manzoor, A.A.; Lindner, L.H.; Landon, C.D.; Park, J.Y.; Simnick, A.J.; Dreher, M.R.; Das, S.; Hanna, G.; Park, W.; Chilkoti, A.; et al. Overcoming limitations in nanoparticle drug delivery: Triggered, intravascular release to improve drug penetration into tumors. Cancer Res. 2012, 72, 5566-5575. [CrossRef]

104. Kong, G.; Anyarambhatla, G.; Petros, W.P.; Braun, R.D.; Colvin, O.M.; Needham, D.; Dewhirst, M.W. Efficacy of liposomes and hyperthermia in a human tumor xenograft model: Importance of triggered drug release. Cancer Res. 2000, 60, 6950-6957.

105. Chen, Q.; Krol, A.; Wright, A.; Needham, D.; Dewhirst, M.W.; Yuan, F. Tumor microvascular permeability is a key determinant for antivascular effects of doxorubicin encapsulated in a temperature sensitive liposome. Int. J. Hyperth. 2008, 24, 475-482. [CrossRef]

106. Chen, Q.; Tong, S.; Dewhirst, M.W.; Yuan, F. Targeting tumor microvessels using doxorubicin encapsulated in a novel thermosensitive liposome. Mol. Cancer Ther. 2004, 3, 1311-1317.

107. Anyarambhatla, G.R.; Needham, D. Enhancement of the phase transition permeability of dppc liposomes by incorporation of mppc: A new temperature-sensitive liposome for use with mild hyperthermia. J. Liposome Res. 1999, 9, 491-506. [CrossRef]

108. Needham, D.; Anyarambhatla, G.; Kong, G.; Dewhirst, M.W. A new temperature-sensitive liposome for use with mild hyperthermia: Characterization and testing in a human tumor xenograft model. Cancer Res. 2000, 60, 1197-1201.

109. Mills, J.K.; Needham, D. Lysolipid incorporation in dipalmitoylphosphatidylcholine bilayer membranes enhances the ion permeability and drug release rates at the membrane phase transition. Biochim. Biophys. Acta 2005, 1716, 77-96. [CrossRef]

110. Zagar, T.M.; Vujaskovic, Z.; Formenti, S.; Rugo, H.; Muggia, F.; O’Connor, B.; Myerson, R.; Stauffer, P.; Hsu, I.C.; Diederich, C.; et al. Two phase i dose-escalation/pharmacokinetics studies of low temperature liposomal doxorubicin (ltld) and mild local hyperthermia in heavily pretreated patients with local regionally recurrent breast cancer. Int. J. Hyperth. 2014, 30, 285-294. [CrossRef]

111. Tagami, T.; Ernsting, M.J.; Li, S.D. Optimization of a novel and improved thermosensitive liposome formulated with dppc and a brij surfactant using a robust in vitro system. J. Control. Release 2011, 154, 290-297. [CrossRef]

112. Tagami, T.; Ernsting, M.J.; Li, S.D. Efficient tumor regression by a single and low dose treatment with a novel and enhanced formulation of thermosensitive liposomal doxorubicin. J. Control. Release 2011, 152, 303-309. [CrossRef]

113. Tagami, T.; May, J.P.; Ernsting, M.J.; Li, S.D. A thermosensitive liposome prepared with a cu(2)(+) gradient demonstrates improved pharmacokinetics, drug delivery and antitumor efficacy. J. Control. Release 2012, 161, 142-149. [CrossRef]

114. Lindner, L.H.; Eichhorn, M.E.; Eibl, H.; Teichert, N.; Schmitt-Sody, M.; Issels, R.D.; Dellian, M. Novel temperature-sensitive liposomes with prolonged circulation time. Clin. Cancer Res. 2004, 10, 2168-2178. [CrossRef]

115. Hossann, M.; Wiggenhorn, M.; Schwerdt, A.; Wachholz, K.; Teichert, N.; Eibl, H.; Issels, R.D.; Lindner, L.H. In vitro stability and content release properties of phosphatidylglyceroglycerol containing thermosensitive liposomes. Biochim. Biophys. Acta 2007, 1768, 2491-2499. [CrossRef]

116. Zimmermann, K.; Hossann, M.; Hirschberger, J.; Troedson, K.; Peller, M.; Schneider, M.; Bruhschwein, A.; Meyer-Lindenberg, A.; Wess, G.; Wergin, M.; et al. A pilot trial of doxorubicin containing phosphatidyldiglycerol based thermosensitive liposomes in spontaneous feline soft tissue sarcoma. Int. J. Hyperth. 2017, 33, 178-190. [CrossRef]

117. Schmaljohann, D. Thermo- and ph-responsive polymers in drug delivery. Adv. Drug Deliv. Rev. 2006, 58, 1655-1670. [CrossRef]

118. Bordat, A.; Boissenot, T.; Nicolas, J.; Tsapis, N. Thermoresponsive polymer nanocarriers for biomedical applications. Adv. Drug Deliv. Rev. 2019, 138, 167-192. [CrossRef]

119. Heskins, M.; Guillet, J.E. Solution properties of poly(n-isopropylacrylamide). J. Macromol. Sci. Part A Chem. 1968, 2, 1441-1455. [CrossRef]

120. Tu, X.Y.; Meng, C.; Wang, Y.F.; Ma, L.W.; Wang, B.Y.; He, J.L.; Ni, P.H.; Ji, X.L.; Liu, M.Z.; Wei, H. Fabrication of thermosensitive cyclic brush copolymer with enhanced therapeutic efficacy for anticancer drug delivery. Macromol. Rapid Commun. 2018, 39, 1700744. [CrossRef] 
121. Cheng, C.C.; Liang, M.C.; Liao, Z.S.; Huang, J.J.; Lee, D.J. Self-assembled supramolecular nanogels as a safe and effective drug delivery vector for cancer therapy. Macromol. Biosci. 2017, 17, 1600370. [CrossRef]

122. Mackay, J.A.; Chilkoti, A. Temperature sensitive peptides: Engineering hyperthermia-directed therapeutics. Int. J. Hyperther. 2008, 24, 483-495. [CrossRef]

123. McDaniel, J.R.; Radford, D.C.; Chilkoti, A. A unified model for de novo design of elastin-like polypeptides with tunable inverse transition temperatures. Biomacromolecules 2013, 14, 2866-2872. [CrossRef]

124. Wu, C.; Wang, X.H. Globule-to-coil transition of a single homopolymer chain in solution. Phys. Rev. Lett. 1998, 80, 4092-4094. [CrossRef]

125. Aseyev, V.; Tenhu, H.; Winnik, F.M. Non-ionic thermoresponsive polymers in water. Adv. Polym. Sci. 2011, $242,29-89$.

126. Zhang, J.; Qian, Z.; Gu, Y. In vivo anti-tumor efficacy of docetaxel-loaded thermally responsive nanohydrogel. Nanotechnology 2009, 20, 325102. [CrossRef]

127. Ku, B.; Seo, H.I.; Chung, B.G. Synthesis and characterization of thermoresponsive polymeric nanoparticles. BioChip J. 2014, 8, 8-14. [CrossRef]

128. Wang, X.; Li, S.; Wan, Z.; Quan, Z.; Tan, Q. Investigation of thermo-sensitive amphiphilic micelles as drug carriers for chemotherapy in cholangiocarcinoma in vitro and in vivo. Int. J. Pharm. 2014, 463, 81-88. [CrossRef]

129. Cammas, S.; Suzuki, K.; Sone, C.; Sakurai, Y.; Kataoka, K.; Okano, T. Thermo-responsive polymer nanoparticles with a core-shell micelle structure as site-specific drug carriers. J. Control. Release 1997, 48, 157-164. [CrossRef]

130. Chung, J.E.; Yokoyama, M.; Yamato, M.; Aoyagi, T.; Sakurai, Y.; Okano, T. Thermo-responsive drug delivery from polymeric micelles constructed using block copolymers of poly(n-isopropylacrylamide) and poly(butylmethacrylate). J. Control. Release 1999, 62, 115-127. [CrossRef]

131. Wei, H.; Zhang, X.Z.; Zhou, Y.; Cheng, S.X.; Zhuo, R.X. Self-assembled thermoresponsive micelles of poly(n-isopropylacrylamide-b-methyl methacrylate). Biomaterials 2006, 27, 2028-2034. [CrossRef]

132. Sun, X.L.; Tsai, P.C.; Bhat, R.; Bonder, E.M.; Michniak-Kohn, B.; Pietrangelo, A. Thermoresponsive block copolymer micelles with tunable pyrrolidone-based polymer cores: Structure/property correlations and application as drug carriers. J. Mater. Chem. B 2015, 3, 814-823. [CrossRef]

133. Cheng, C.C.; Chang, F.C.; Kao, W.Y.; Hwang, S.M.; Liao, L.C.; Chang, Y.J.; Liang, M.C.; Chen, J.K.; Lee, D.J. Highly efficient drug delivery systems based on functional supramolecular polymers: In vitro evaluation. Acta Biomater. 2016, 33, 194-202. [CrossRef]

134. van Elk, M.; Murphy, B.P.; Eufrasio-da-Silva, T.; O’Reilly, D.P.; Vermonden, T.; Hennink, W.E.; Duffy, G.P.; Ruiz-Hernandez, E. Nanomedicines for advanced cancer treatments: Transitioning towards responsive systems. Int. J. Pharm. 2016, 515, 132-164. [CrossRef]

135. Akimoto, J.; Nakayama, M.; Sakai, K.; Okano, T. Thermally controlled intracellular uptake system of polymeric micelles possessing poly(n-isopropylacrylamide)-based outer coronas. Mol. Pharm. 2010, 7, 926-935. [CrossRef]

136. Raucher, D.; Chilkoti, A. Enhanced uptake of a thermally responsive polypeptide by tumor cells in response to its hyperthermia-mediated phase transition. Cancer Res. 2001, 61, 7163-7170.

137. Akimoto, J.; Nakayama, M.; Sakai, K.; Okano, T. Temperature-induced intracellular uptake of thermoresponsive polymeric micelles. Biomacromolecules 2009, 10, 1331-1336. [CrossRef]

138. McDaniel, J.R.; MacEwan, S.R.; Dewhirst, M.; Chilkoti, A. Doxorubicin-conjugated chimeric polypeptide nanoparticles that respond to mild hyperthermia. J. Control. Release 2012, 159, 362-367. [CrossRef]

139. Kohori, F.; Sakai, K.; Aoyagi, T.; Yokoyama, M.; Sakurai, Y.; Okano, T. Preparation and characterization of thermally responsive block copolymer micelles comprising poly(n-isopropylacrylamide-b-dl-lactide). J. Control. Release 1998, 55, 87-98. [CrossRef]

140. Yang, M.; Ding, Y.; Zhang, L.; Qian, X.; Jiang, X.; Liu, B. Novel thermosensitive polymeric micelles for docetaxel delivery. J. Biomed. Mater. Res. A 2007, 81, 847-857. [CrossRef]

141. Sun, F.L.; Wang, Y.X.; Wei, Y.; Cheng, G.; Ma, G.H. Thermo-triggered drug delivery from polymeric micelles of poly(n-isopropylacrylamide-co-acrylamide)-b-poly(n-butyl methacrylate) for tumor targeting. J. Bioact. Compat. Polym. 2014, 29, 301-317. [CrossRef]

142. Panja, S.; Dey, G.; Bharti, R.; Kumari, K.; Maiti, T.K.; Mandal, M.; Chattopadhyay, S. Tailor-made temperature-sensitive micelle for targeted and on-demand release of anticancer drugs. ACS Appl. Mater. Interfaces 2016, 8, 12063-12074. [CrossRef] 
143. Ringsdorf, H.; Venzmer, J.; Winnik, F.M. Interaction of hydrophobically-modified poly-nisopropylacrylamides with model membranes-Or playing a molecular accordion. Angew. Chem. Int. Ed. 1991, 30, 315-318. [CrossRef]

144. Wu, X.S.; Hoffman, A.S.; Yager, P. Conjugation of phosphatidylethanolamine to poly(n-isopropylacrylamide) for potential use in liposomal drug delivery systems. Polymer 1992, 33, 4659-4662. [CrossRef]

145. Kono, K.; Hayashi, H.; Takagishi, T. Temperature-sensitive liposomes-Liposomes bearing poly(n-isopropylacrylamide). J. Control. Release 1994, 30, 69-75. [CrossRef]

146. van Elk, M.; Deckers, R.; Oerlemans, C.; Shi, Y.; Storm, G.; Vermonden, T.; Hennink, W.E. Triggered release of doxorubicin from temperature-sensitive poly(n-(2-hydroxypropyl)-methacrylamide mono/dilactate) grafted liposomes. Biomacromolecules 2014, 15, 1002-1009. [CrossRef]

147. Paasonen, L.; Romberg, B.; Storm, G.; Yliperttula, M.; Urtti, A.; Hennink, W.E. Temperature-sensitive poly(n-(2-hydroxypropyl)methacrylamide mono/dilactate)-coated liposomes for triggered contents release. Bioconjug. Chem. 2007, 18, 2131-2136. [CrossRef]

148. Mo, Y.L.; Du, H.L.; Chen, B.L.; Liu, D.C.; Yin, Q.Q.; Yan, Y.; Wang, Z.H.; Wan, F.J.; Qi, T.; Wang, Y.Q.; et al. Quick-responsive polymer-based thermosensitive liposomes for controlled doxorubicin release and chemotherapy. ACS Biomater. Sci. Eng. 2019, 5, 2316-2329. [CrossRef]

149. Kono, K.; Henmi, A.; Takagishi, T. Temperature-controlled interaction of thermosensitive polymer-modified cationic liposomes with negatively charged phospholipid membranes. Bba-Biomembranes 1999, 1421, $183-197$. [CrossRef]

150. Kono, K.; Yoshino, K.; Takagishi, T. Effect of poly(ethylene glycol) grafts on temperature-sensitivity of thermosensitive polymer-modified liposomes. J. Control. Release 2002, 80, 321-332. [CrossRef]

151. Kono, K.; Murakami, T.; Yoshida, T.; Haba, Y.; Kanaoka, S.; Takagishi, T.; Aoshima, S. Temperature sensitization of liposomes by use of thermosensitive block copolymers synthesized by living cationic polymerization: Effect of copolymer chain length. Bioconjug. Chem. 2005, 16, 1367-1374. [CrossRef]

152. Kono, K.; Ozawa, T.; Yoshida, T.; Ozaki, F.; Ishizaka, Y.; Maruyama, K.; Kojima, C.; Harada, A.; Aoshima, S. Highly temperature-sensitive liposomes based on a thermosensitive block copolymer for tumor-specific chemotherapy. Biomaterials 2010, 31, 7096-7105. [CrossRef]

153. Kono, K.; Nakashima, S.; Kokuryo, D.; Aoki, I.; Shimomoto, H.; Aoshima, S.; Maruyama, K.; Yuba, E.; Kojima, C.; Harada, A.; et al. Multi-functional liposomes having temperature-triggered release and magnetic resonance imaging for tumor-specific chemotherapy. Biomaterials 2011, 32, 1387-1395. [CrossRef]

154. Kokuryo, D.; Nakashima, S.; Ozaki, F.; Yuba, E.; Chuang, K.H.; Aoshima, S.; Ishizaka, Y.; Saga, T.; Kono, K.; Aoki, I. Evaluation of thermo-triggered drug release in intramuscular-transplanted tumors using thermosensitive polymer-modified liposomes and mri. Nanomedicine 2015, 11, 229-238. [CrossRef]

155. Na, K.; Lee, S.A.; Jung, S.H.; Hyun, J.; Shin, B.C. Elastin-like polypeptide modified liposomes for enhancing cellular uptake into tumor cells. Colloid Surf. B 2012, 91, 130-136. [CrossRef]

156. Park, S.M.; Kim, M.S.; Park, S.J.; Park, E.S.; Choi, K.S.; Kim, Y.S.; Kim, H.R. Novel temperature-triggered liposome with high stability: Formulation, in vitro evaluation, and in vivo study combined with high-intensity focused ultrasound (hifu). J. Control. Release 2013, 170, 373-379. [CrossRef]

157. Al-Ahmady, Z.S.; Al-Jamal, W.T.; Bossche, J.V.; Bui, T.T.; Drake, A.F.; Mason, A.J.; Kostarelos, K. Lipid-peptide vesicle nanoscale hybrids for triggered drug release by mild hyperthermia in vitro and in vivo. ACS Nano 2012, 6, 9335-9346. [CrossRef]

158. Jadhav, S.V.; Singh, S.K.; Reja, R.M.; Gopi, H.N. Gamma-amino acid mutated alpha-coiled coils as mild thermal triggers for liposome delivery. Chem. Commun. 2013, 49, 11065-11067. [CrossRef]

159. Wang, J.; Ayano, E.; Maitani, Y.; Kanazawa, H. Tunable surface properties of temperature-responsive polymer-modified liposomes induce faster cellular uptake. ACS Omega 2017, 2, 316-325. [CrossRef]

160. Hayashi, H.; Kono, K.; Takagishi, T. Temperature-controlled release property of phospholipid vesicles bearing a thermo-sensitive polymer. Bba-Biomembranes 1996, 1280, 127-134. [CrossRef]

161. Kim, J.C.; Bae, S.K.; Kim, J.D. Temperature-sensitivity of liposomal lipid bilayers mixed with poly(n-isopropylacrylamide-co-acrylic acid). J. Biochem.-Tokyo 1997, 121, 15-19. [CrossRef]

162. Kono, K.; Nakai, R.; Morimoto, K.; Takagishi, T. Thermosensitive polymer-modified liposomes that release contents around physiological temperature. Biochim. Biophys. Acta 1999, 1416, 239-250. [CrossRef]

163. Kono, K.; Henmi, A.; Yamashita, H.; Hayashi, H.; Takagishi, T. Improvement of temperature-sensitivity of poly(n-isopropylacrylamide)-modified liposomes. J. Control. Release 1999, 59, 63-75. [CrossRef] 
164. Ta, T.; Convertine, A.J.; Reyes, C.R.; Stayton, P.S.; Porter, T.M. Thermosensitive liposomes modified with poly(n-isopropylacrylamide-co-propylacrylic acid) copolymers for triggered release of doxorubicin. Biomacromolecules 2010, 11, 1915-1920. [CrossRef]

165. Kono, K.; Nakai, R.; Morimoto, K.; Takagishi, T. Temperature-dependent interaction of thermo-sensitive polymer-modified liposomes with cv1 cells. FEBS Lett. 1999, 456, 306-310. [CrossRef]

166. Yoshino, K.; Kadowaki, A.; Takagishi, T.; Kono, K. Temperature sensitization of liposomes by use of n-isopropylacrylamide copolymers with varying transition endotherms. Bioconjug. Chem. 2004, 15, 1102-1109. [CrossRef]

167. Han, H.D.; Shin, B.C.; Choi, H.S. Doxorubicin-encapsulated thermosensitive liposomes modified with poly(n-isopropylacrylamide-co-acrylamide): Drug release behavior and stability in the presence of serum. Eur. J. Pharm. Biopharm. 2006, 62, 110-116. [CrossRef]

168. Han, H.D.; Choi, M.S.; Hwang, T.; Song, C.K.; Seong, H.; Kim, T.W.; Choi, H.S.; Shin, B.C. Hyperthermia-induced antitumor activity of thermosensitive polymer modified temperature-sensitive liposomes. J. Pharm. Sci. 2006, 95, 1909-1917. [CrossRef]

169. Klemetsrud, T.; Hiorth, M.; Smistad, G.; Kjoniksen, A.L. Characterization of temperature induced changes in liposomes coated with poly(n-isopropylacrylamide-co-methacrylic acid). J. Colloid Interface Sci. 2015, 450, 7-16. [CrossRef]

170. Ta, T.; Bartolak-Suki, E.; Park, E.J.; Karrobi, K.; McDannold, N.J.; Porter, T.M. Localized delivery of doxorubicin in vivo from polymer-modified thermosensitive liposomes with mr-guided focused ultrasound-mediated heating. J. Control. Release 2014, 194, 71-81. [CrossRef]

171. Soga, O.; van Nostrum, C.F.; Hennink, W.E. Poly(n-(2-hydroxypropyl) methacrylamide mono/di lactate): A new class of biodegradable polymers with tuneable thermosensitivity. Biomacromolecules 2004, 5, 818-821. [CrossRef]

172. Chilkoti, A.; Dreher, M.R.; Meyer, D.E.; Raucher, D. Targeted drug delivery by thermally responsive polymers. Adv. Drug Deliv. Rev. 2002, 54, 613-630. [CrossRef]

Publisher's Note: MDPI stays neutral with regard to jurisdictional claims in published maps and institutional affiliations.

(C) 2020 by the authors. Licensee MDPI, Basel, Switzerland. This article is an open access article distributed under the terms and conditions of the Creative Commons Attribution (CC BY) license (http://creativecommons.org/licenses/by/4.0/). 